\title{
Postpartum Ultrasound
}

\author{
Ajlana Mulic-Lutvica
}

\section{ABSTRACT}

This article describes uterine and uterine cavity changes throughout the normal and pathological puerperium, as revealed by various ultrasound modalities. A gray scale ultrasound, color and pulsed Doppler ultrasound and 3D ultrasound were used. It is based on results of several prospective longitudinal studies, which were designed so that every woman was examined at six occasions during the puerperium, namely on postpartum days $1,3,7,14,28$ and 56 . The first four examinations were performed transabdominally and the last two transvaginally. The same design was used in all studies. The involution process of the uterus was assessed by measuring the anteroposterior diameter of the uterus and uterine cavity. Morphological findings were recorded. The influence on the involution process of parity, breastfeeding, maternal smoking and infant's birth weight were also evaluated. Besides conventional ultrasound, Doppler technology was used to study hemodynamic events occurring during the normal puerperium. The pulsatility $(\mathrm{PI})$ and resistance (RI) indices in the uterine arteries were measured, and the presence or absence of early diastolic notches was recorded. A hypervascular area in myometrium was assessed by color and power Doppler. Normal involution process was also described by means of 3D ultrasound. The volume of the uterus and uterine cavity after normal vaginal delivery were measured using virtual organ computer-aided analysis (VOCAL) using six adjacent planes and a $30^{\circ}$ rotation method. Reference values from uncomplicated puerperium were used when pathological conditions were studied.

Results from these studies, which shed light on normal and pathological changes during the puerperium, are summarized in this chapter.

Keywords: Normal puerperium, Ultrasound, Uterus, Uterine cavity, Doppler, Uterine artery, 3D postpartum, VOCAL, Pathological puerperium.

How to cite this article: Mulic-Lutvica A. Postpartum Ultrasound. Donald School J Ultrasound Obstet Gynecol 2012; 6(1):76-92.

\section{Source of support: Nil}

Conflict of interest: None declared

\section{INTRODUCTION}

Postpartum period usually includes six subsequent weeks during which normal pregnancy involution occurs and the uterus returns to the nonpregnant state. Our knowledge about postpartum changes in the uterus has mainly been based on clinical examinations as well as from histological studies from the end of the 19th century and the early part of the 20th century when maternal mortality was high. ${ }^{1}$ The involution of the uterus, as a main characteristic of the puerperium was previously assessed by palpation of the fundal height.
Since, the introduction of ultrasound (USG) in clinical practice by Ian Donald et $\mathrm{al}^{2}$ in 1958 the uterus became one of the first organs to be examined. ${ }^{3-7}$ However, few studies have focused on USG investigations during the puerperium and results of published studies are not unambiguous. ${ }^{1-16}$ In published studies concerning the involution process, the length, ${ }^{4,6-9,11,12,14}$ width, ${ }^{8,9,12}$ anteroposterior diameter, ${ }^{3-7,11-13,16}$ area, ${ }^{9}$ thickness of the uterine wall ${ }^{10}$ and volume of the uterus and the uterine cavity, ${ }^{15}$ have been used as a measure of uterine involution. Majority of the studies described pathological conditions without knowledge about normal findings, ${ }^{4,5,8}$ they were restricted to the early puerperium and designs were crosssectional. ${ }^{3-7,12}$ A few studies concerning uterine cavity during normal puerperium have been published. ${ }^{13-16}$

Postpartum complications involving the uterus occur in about 8 to $10 \%$ of cases. Immediate and late postpartum hemorrhage, puerperal sepsis and septic pelvic thromboembolism are still potentially life-threatening conditions. Abnormal placentation (placenta accreta, increta or percreta) is a rare cause of postpartum hemorrhage that may continue after delivery. Several studies investigated antenatal ultrasound diagnosis of this condition ${ }^{17-23}$ but a few papers have focused on postpartum ultrasound monitoring of retained placenta accreta. ${ }^{24}$ Ultrasound can help to diagnose vascular lesions, congenital or acquired, ${ }^{25-31}$ placental site tumor $^{32}$ and choriocarcinoma, which can also cause severe postpartum hemorrhage.

Thus, whenever puerperal complication occurs, the obstetricians should not hesitate to switch on ultrasound machine.

\section{NORMAL PUERPERIUM}

A description of normal ultrasound changes of the uterus and uterine cavity during puerperium is a prerequisite for ultrasound diagnosis of pathological conditions. We can follow the physiological involution of the uterus weighing more than $1 \mathrm{~kg}$ soon after delivery to an organ weighing about $80 \mathrm{gm}$ at the end of the puerperium by means of ultrasound. The involution changes concerning the size, shape, position and texture of the uterus have been relatively well-examined by ultrasound. ${ }^{3-16}$ The influence on the involution process of parity, ${ }^{7,9,11,13,15,16}$ route of delivery, ${ }^{11}$ oxytocin administration during labor ${ }^{7}$ breastfeeding, 6,9,11-13,15,16 or the infant's weight ${ }^{11-13}$ have been studied. Previously published studies 
involving sonographic examination of uterine cavity are not unambiguous. ${ }^{6,11,13-16}$

In the early and middle puerperium (in the first 2 weeks) the transabdominal approach is to be recommended. A relatively short focal length of the vaginal probe limits its use during the early postpartum period, when the uterus is too large and lies near the abdominal wall. In contrast, during the late postpartum period (> 2 weeks) a high frequency transvaginal probe, which better distinguishes minor details, should be used. At that time, the uterus is considerably decreased in size and it lies in the true pelvis. The postpartum uterus should be examined in three standard sections: sagittal, transverse and coronal (Figs 1 and 2). Urinary bladder should be moderately filled. Gentle compression with the probe should be used in order to avoid uterine distortion.

We can differentiate three typical ultrasound images during normal puerperium: In the early, middle and late puerperium (Figs 3 and 4). The involution of the uterus is a dynamic process that has no parallel process in normal adult life. ${ }^{1}$ There are two physiological lifesaving processes occurring soon after placenta delivery:

1. Myotamponade (compression of the vessels by myometrial contraction).

2. Thrombotamponade (enhanced blood clotting activity).

The appearance of ultrasound finding in the early postpartum period reflects these physiological changes. The uterus has an angulated form (Fig. 4A). It lies in a slightly retroflexed position and arches over the sacral promontory. Wachsberg et $\mathrm{al}^{12}$ pointed out the impact of uterine angulation on the measurement of uterine length and recommended segmental measurement. This angulated form of the early puerperal uterus is typical only in early puerperium and it is artificial. An extremely great degree of uterine deformability is caused by a heavy uterine corpus, a hypotonic lower uterine segment and supine position of the examined woman. Lifesaving uterine contraction approaches anterior and posterior uterine walls and just a virtual cavity appears. The uterine cavity is empty and decidua appears as a thin white line from the fundus to the level of the internal cervical os (Fig. 4A). Sometimes, this

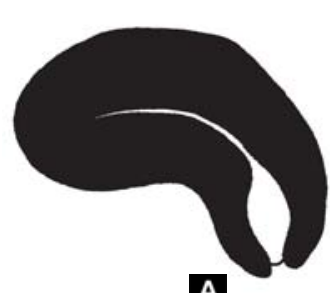

A

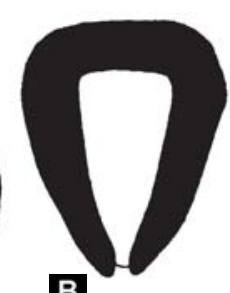

B

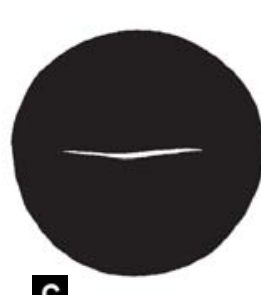

c
Figs 1A to C: Three standard ultrasound sections of the puerperal uterus: (A) Longitudinal; (B) Coronal; (C) Transverse line can be irregular and thicker, which probably depends on the amount of retained decidua (Fig. 5A). The separation of the placenta and membranes generally occurs in the spongy layer; however the level varies. In 1931, Williams wrote concerning the line of separation of the placenta and membranes: 'While separation generally occurs in the spongy layer, the line is very irregular so that in places a thick layer of decidua is retained, in others only a few layers
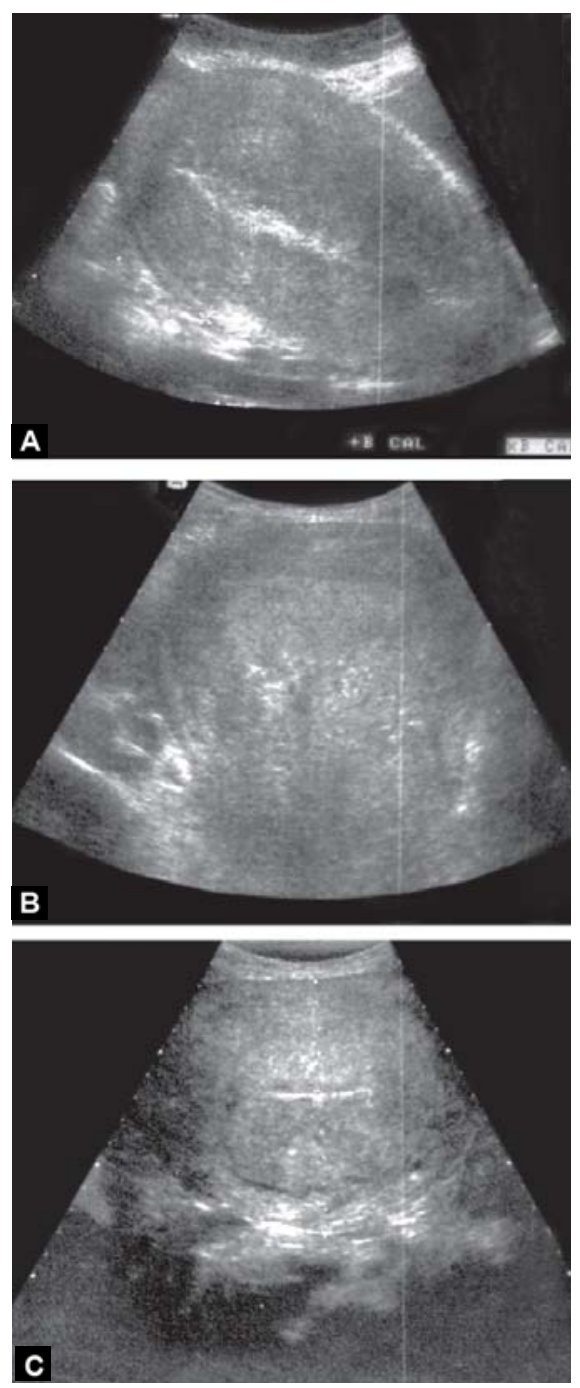

Figs 2A to C: Transabdominal ultrasound scans of a normal puerperal uterus on day 1: (A) Longitudinal scan; (B) Coronal scan; (C) Transverse scan
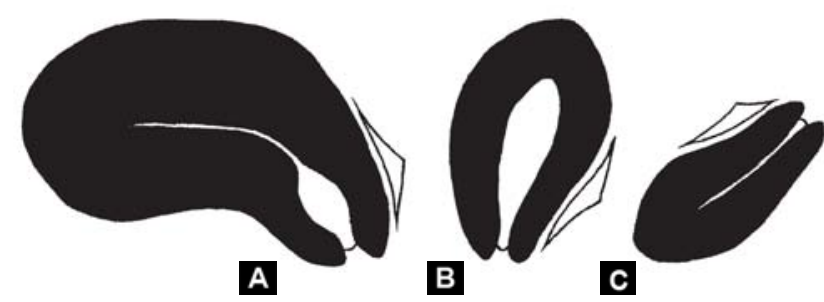

Figs $3 \mathbf{A}$ to $\mathbf{C}$ : The normal ultrasound appearance of the uterus and uterine cavity during the puerperium: (A) Transabdominal approach during the early puerperium; (B) During the middle part of the puerperium; (C) Transvaginal approach during the late puerperium 

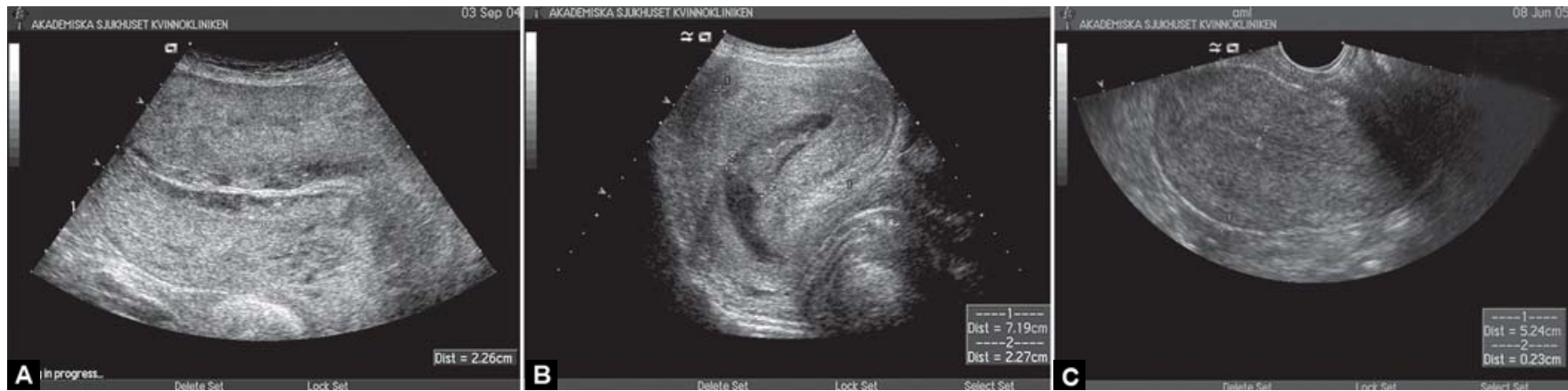

Figs 4A to C: Three typical USG images during normal puerperium: (A) In the early puerperium: uterus is retroverted. The cavity is seen as a thin white line; (B) In the middle puerperium: uterus is anteverted. An abundant fluid or mixed echo pattern with echogenic and echofree area is seen in the whole cavity; $(C)$ In the late puerperium: uterus is considerably decreased in size; the cavity is empty and appears as a thin white line
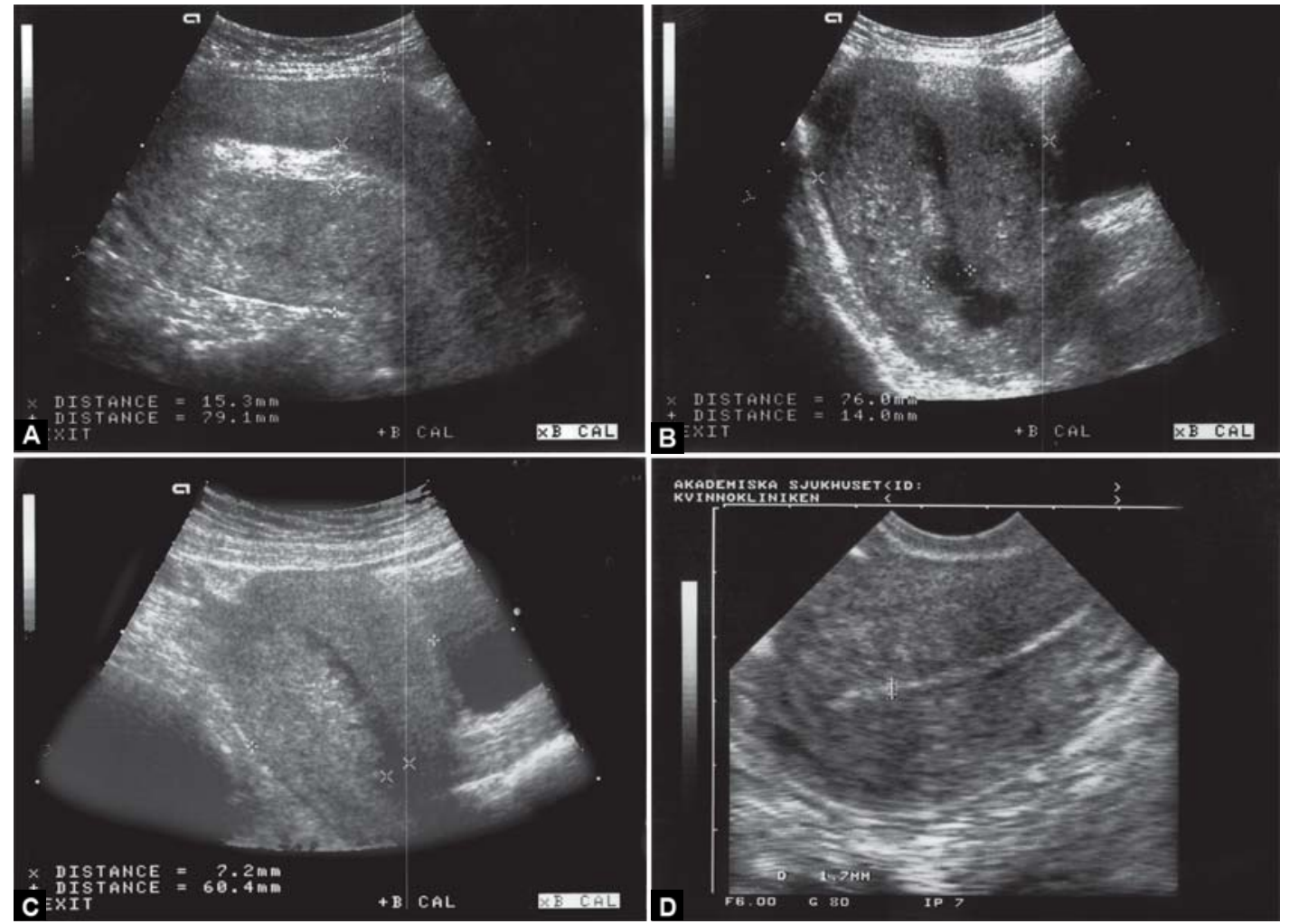

Figs 5A to D: Transabdominal, longitudinal scans of the uterus from an uncomplicated puerperium: (A) On day 1;

(B) On day 7; (C) On day 14; (D) On day 28

of cells remain, while in still others the muscularis is practically bare". ${ }^{33}$ The variation in sonographic appearance of the cavity could be seen as a demonstration of these physiological variations in retained decidua. The white thin line seen on ultrasound might possibly represent cases in which only the basal decidual layer is retained or if the muscularis is practically bare (Fig. 4A). Whereas the thicker and more irregular lines might represent cases with retention of more amount of spongy decidual layer and perhaps fragments of membranes (Fig. 5A).

Fluid or echogenic mass is not common finding in the cavity in the early postpartum period. ${ }^{13}$ Small echogenic or echolucent dots in the cavity are harmless physiological findings. ${ }^{13,34}$ A heterogeneous mass with fluid and solid components can be seen in the cervical area. ${ }^{13,14,34,35}$ This finding has no clinical significance and the mass is usually expelled spontaneously. It probably reflects a collection of blood, blood clots and parts of membranes. On the posterior wall of the uterus the prominent uterine vascular channels are regularly seen. ${ }^{11}$ They usually disappear during the 2nd and 3rd postpartum weeks as a result of involution process, which decreases both the size and the amount of uterine vessels. Gas in the cavity is not common finding in the early postpartum period although it can be occasionally seen. ${ }^{13}$ Wachsberg detected gas in 19\% of normal population during the early postpartum period. ${ }^{36}$ 
In the middle part of the puerperium (1-2 weeks postpartum) the uterus is diminished, the shape of the uterus is oval. It rotates along its internal cervical os toward an anteflexed position probably due to forming a firm isthmus. ${ }^{13}$ The vascular channels are not so prominent. Either pure fluid or mixed echo with fluid and solid components can be seen in the whole cavity not only in the cervical area (Figs 4B, 5B and C). This finding reflects a normal healing process of the placental site inside uterine cavity, necrotic changes of retained decidua and an abundant shedding of lochia. Echogenic mass or gas is not common finding during middle part of the puerperium. In contrast Edwards et $\mathrm{al}^{15}$ found an echogenic mass in a great proportion of normal puerperal women.

During late puerperium ( $>2$ weeks postpartum), the uterus is considerably diminished (Figs 4C and 5D). It lies in an anteflexed position in $88 \%$ of cases. ${ }^{13}$ In $12 \%$ of cases the uterus has a retroflexed position corresponding well to normal prevalence of retroversion of the uterus in general population (Fig. 6A). The uterine cavity is again empty. Decidua and necrotic vessel ends are exfoliated, the placental site is recovered and a new endometrium is regenerated from the basal layer of the decidua adjacent to the myometrium. Ultrasonically the cavity in the late puerperium appears as a thin white line (Figs 4C and 5D). This corresponds to an inactive endometrium and reflects the hypoestrogenic state of the puerperium ('the physiologic menopause'). Sometimes, a small amount of fluid or echogenic dots can be seen (arrow) (Fig. 6B).

In 1953, Sharman performed endometrium biopsies and identified fully restored endometrium from the 16th postpartum day ${ }^{37}$ In contrast, a study published in 1986 by Oppenheimer ${ }^{38}$ showed that duration of puerperal lochia may be up to 60 days in $13 \%$ of women. Similarly in a recently published study, ${ }^{39}$ on the duration of postpartum bleeding among 477 breastfeeding women, it was reported that the median duration of lochia was 27 days with a range from 5 to 90 days. Only 15\% of the women reported that their lochia had stopped within two weeks postpartum. They also pointed to the fact that bleeding associated with the postpartum healing process commonly stops and starts again. So, the normal physiological time span for the placental site to recover is probably 4 to 6 weeks and not two weeks as previously considered.

\section{Doppler Ultrasound During Normal Puerperium}

Besides conventional ultrasound, Doppler technology is used to study hemodynamic events occurring during the puerperium. Normal pregnancy requires the growth of many new vessels. Consequently, during puerperium dramatically regressive changes must occur. The physiological involution of the uterus involves not only muscle cells and decidua but also the arteries. From histological studies, we know that normal involuted placental bed is characterized by a disappearance of trophoblasts and completely thrombosed spiral arteries. ${ }^{40-42}$ High diastolic flow velocities in combination with a disappearance of the early diastolic notch are the main characteristics of the uterine artery Doppler flow pattern from gestational week 20 to 26 and they reflect the physiological conversion from high (nonpregnant) to low (pregnant) resistance state. ${ }^{43,44}$ How fast these physiological changes return to the nonpregnant state is a controversial issue. ${ }^{45-48}$ Tekay and Jouppila ${ }^{14}$ assessed the peripheral vascular resistance of the uterine arteries in 42 postpartum women and found that the pulsatility index (PI) increased significantly in early puerperium compared to pregnancy, remained unchanged during the next 6 weeks and then gradually started to increase again. However, nonpregnant values were not reached even three months after delivery. Jaffa et al, ${ }^{46}$ on the other hand, described that PI decreased in the 2nd and remained relatively low until the 4th postpartum week.
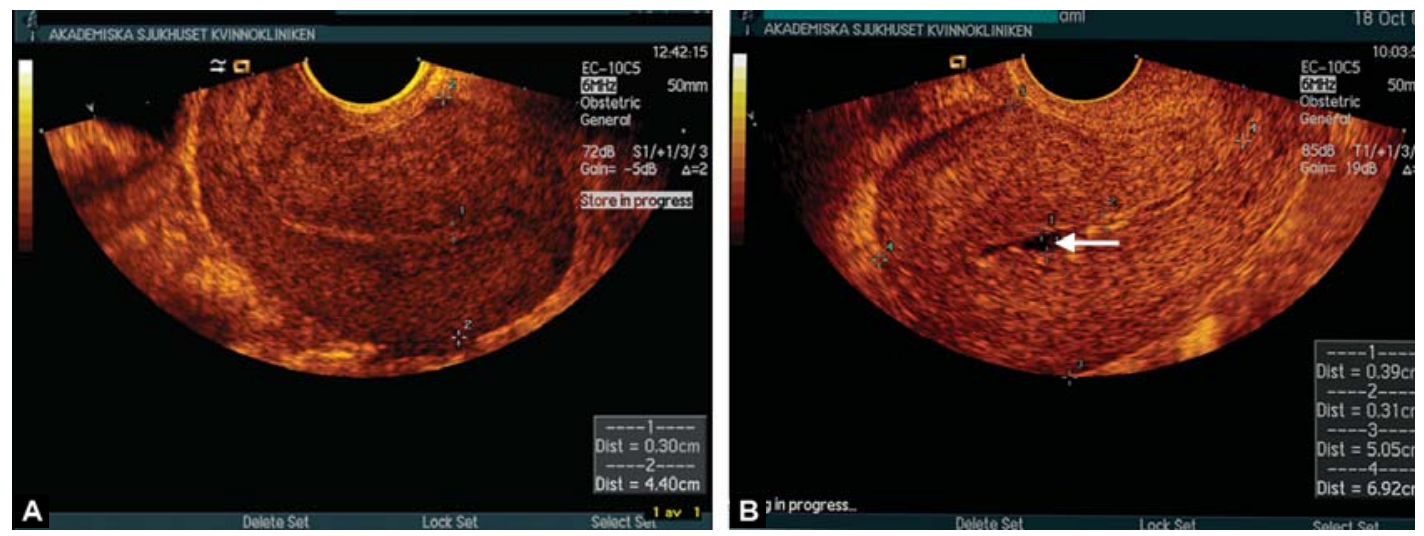

Figs 6A and B: (A) Transvaginal ultrasound image of the uterus on day 28 postpartum shows a retroverted uterus on day 28 postpartum; (B) Transvaginal ultrasound image of the uterus on day 28 postpartum shows a small amount of fluid with echogenic foci in the cavity (white arrow) 
Similar differences regarding the reappearance of the early diastolic notch have been reported. Tekay and Jouppila ${ }^{14}$ noted a reappearance of the early diastolic notch already in early puerperium in 40 of 42 women, while Jaffa et $\mathrm{al}^{46}$ found that the early diastolic notch had reappeared in only one of 60 women five weeks postpartum.

According to our findings, ${ }^{48}$ in early puerperium the means of Doppler flow resistance indices are higher than those reported in late pregnancy. Thereafter, they do not change markedly until day 28 postpartum. On day 56 postpartum, they are still lower compared to the values reported for nonpregnant women, which speaks for longer duration of physiological vascular return from a pregnant to a nonpregnant state. We observed a diastolic notch in $13 \%$ of women on day one and in $90.6 \%$ of women on day 56 postpartum (Figs 7A and B).

Color and power Doppler ultrasound may detect a localized area of increased vascularity within the myometrium. It may be a common transient ultrasound finding if asymptomatic and it does not require treatment. ${ }^{47}$

\section{THREE-DIMENSIONAL ULTRASOUND POSTPARTUM}

Although the volume of the uterus and uterine cavity were previously measured using $2 \mathrm{D}$ ultrasound, ${ }^{15}$ the volumes

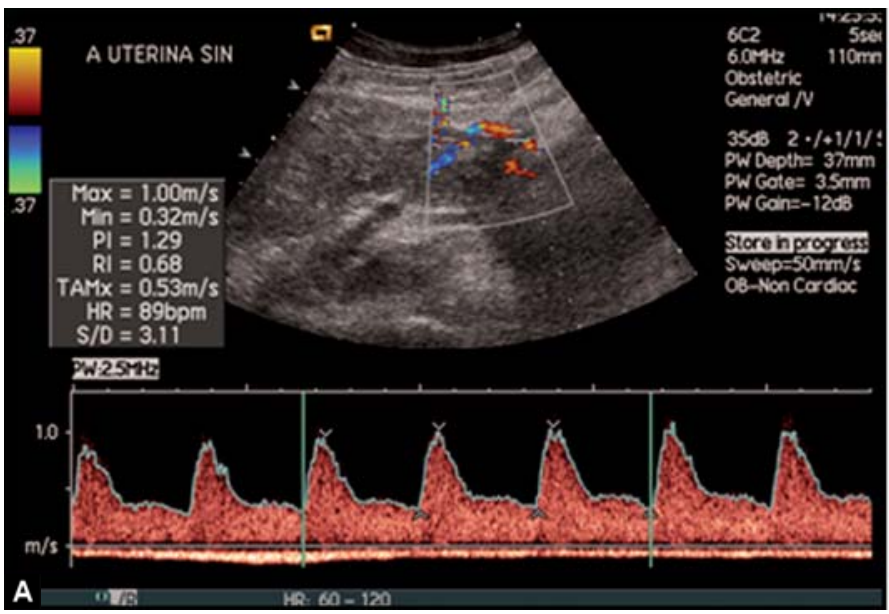

assessed by 3D (three-dimensional) ultrasound may provide more accurate measurements than does the conventional ultrasound. 3D ultrasound using VOCAL program (Virtual Organ Computer-aided Analysis) has recently been used to measure the volumes of the uterus and the uterine cavity after normal delivery. ${ }^{49}$ It is shown in Figures $8 \mathrm{~A}$ and B.

3D power Doppler angiography is a new unexplored method for quantifying noninvasively the vascular network of the uterus (Fig. 8C).

\section{RETAINED PLACENTAL TISSUE}

Both ultrasound diagnosis of RPT (retained placental tissue) and appropriate management for $\mathrm{SPH}$ (secondary postpartum hemorrhage) is still a controversial issue. SPH is defined as any abnormal bleeding from the uterus occurring between 24 hours and 12 weeks postpartum ${ }^{49}$ and occurs in 1 to $2 \%$ of deliveries. ${ }^{50,51}$ In developed countries, half of postpartum women who are admitted to hospital with this condition undergo uterine surgical evacuation. ${ }^{49-53}$ In developing countries, it is a major contributor to maternal death. ${ }^{49}$ The most common causes of SPH are abnormal involution of the placental site in the uterine cavity that may be idiopathic ${ }^{42}$ or it can be caused by RPT ${ }^{54}$ or by endometritis. ${ }^{52}$ Subinvolution of the placental bed in the absence of RPT or

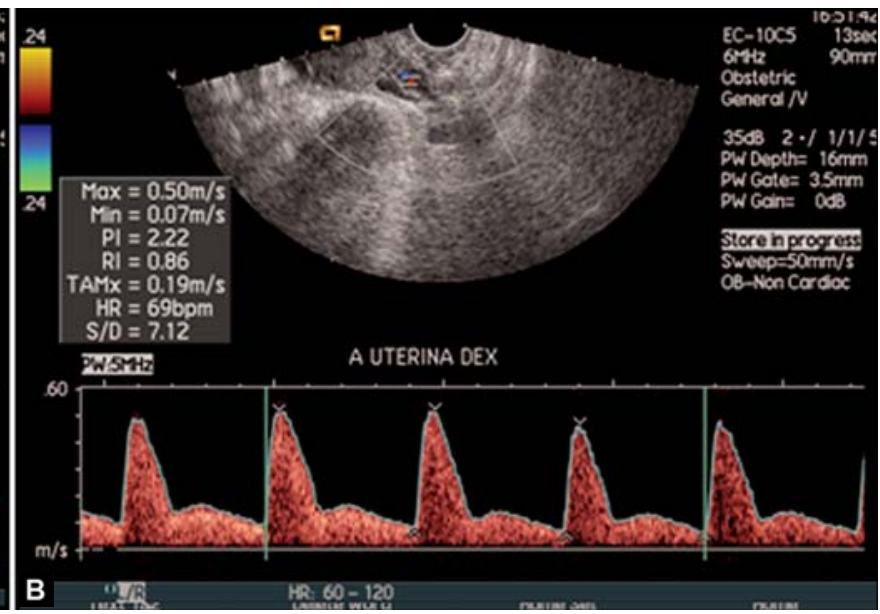

Figs 7A and B: (A) Normal flow velocity waveforms of the uterine artery on day 1 (Transabdominal approach) and; (B) 56 (Transvaginal approach) postpartum

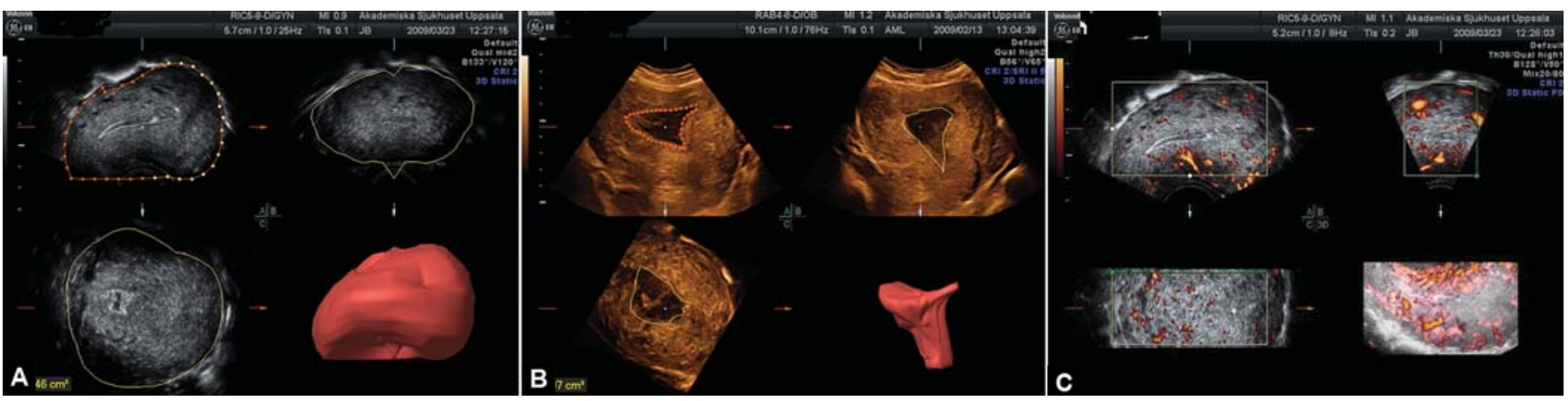

Figs 8A to C: (A) Three-dimensional USG of the volume of the uterus on day 28 and; (B) Uterine cavity on day 7 after normal delivery; (C) With 3D power Doppler a localized area of increased vascularity within the myometrium is seen 
endometritis is a distinctive entity, characterized by widely distended spiral arteries, only partly occluded by thrombi of various ages and invested with extravillous trophoblasts. ${ }^{40,42}$ The diagnosis, however, requires histological examination and clinically it is a diagnosis of exclusion. Moreover, placental vascular subinvolution is often under-recognized by general surgical pathologists. ${ }^{42}$ Carlan et al ${ }^{55}$ performed manual exploration of the cavity on 131 asymptomatic women, 5 minutes after placental delivery and within 2 minutes after an ultrasound examination. They found that 24 of 131(18.8\%) women had documented evidence of RPT. This is a surprisingly higher figure compared to Jones et $\mathrm{al}^{56}$ who performed manual intrauterine explorations routinely after 1000 births and removed placental fragments or bits of membranes in only 2 to $4 \%$ of cases. Defective decidua, which can be scanty or completely absent in some patients, is a predisposing factor for abnormal attachment of the placenta and for partially RPT. ${ }^{40}$ Vascular abnormalities of the uterus have recently been described as possibly more common causes of severe SPH than previously thought. ${ }^{25-31}$

In a Cochrane Review, Alexander et al ${ }^{50}$ identified 45 papers about the management of SPH and concluded that little information is available from randomized trials to guide clinicians in the management of this condition. Since, the causes of SPH may be numerous, the best treatment options should be chosen according to the underlying cause of bleeding. However, an essential problem is that the underlying cause of SPH often is unknown and that clinical or ultrasound diagnosis of RPT, which is the indication for surgical treatment, is still a controversial issue. ${ }^{58-68}$ The decision whether to perform uterine evacuation for RPT depends on both, clinical finding and the ability to visualize retained placenta by ultrasound. ${ }^{58-69}$ Although prompt curettage seems to be necessary, in many cases it usually does not remove identifiable placental tissue. Moreover, it is more likely to traumatize the implantation site and incite more bleeding. Consequently, the complications rate is high. Hoveyda et al reported in his review regarding secondary postpartum hemorrhage that the frequency of perforation of the uterus was $3 \%$ and hysterectomy about $1 \% .{ }^{54}$ Similar results are reported from an audit of 200 cases concerning puerperal curettage. ${ }^{70}$ They showed that $8.5 \%$ of patients experienced major morbidity and $7 \%$ required a repeat procedure with further morbidity. In addition to immediate complications, late sequelae related to surgical treatment for SPH may influence the reproductive health of women. If curettage damages the endometrium 1 to 4 weeks postpartum, the endometrium may fail to regenerate, leading to Asherman's syndrome Jensen and Stromme. ${ }^{71}$ Westendorp et $\mathrm{al}^{72}$ prospectively examined 50 women undergoing either a repeat removal of placental remnants after delivery or a repeat curettage for incomplete abortion. At a later hysteroscopy, 20 out of 50 (40\%) women had intrauterine adhesions. The prevalence of Asherman's syndrome is $2 \%$ after manual evacuation of the placenta but, ${ }^{37} 5 \%$ after postpartum curettage. ${ }^{72}$ Recently, an update on intrauterine adhesions has been published and the importance of prevention has been emphasized. ${ }^{73}$

First studies concerning RPT performed with old ultrasound equipment showed high rate of false-positive diagnosis. ${ }^{4,5,8}$ Similar results have been obtained by modern ultrasound equipment. ${ }^{58-68}$ Published studies have demonstrated a variable sensitivity (42-94\%) and specificity (62-92\%) for ultrasound diagnosis of RPT. ${ }^{58-68}$ On the other side, ultrasound appears as a valuable tool to confirm an empty cavity. Lee and Mandrazzo ${ }^{8}$ found empty cavity in 20 of 27 patients with late puerperal bleeding. In only one case, RPT was confirmed. The same authors reported that histological confirmation was obtained in eight of nine patients with ultrasound suspected RPT. Although ultrasound technology improved considerably, the diagnosis of RPT is still difficult. Ultrasound finding of RPT may vary depending on many different factors. We cannot expect the same ultrasound image during early (Figs 4A and 5A) and late period of the puerperium (Figs 4C and 5D). The presence of blood, blood clots, necrotic decidua, membranes or gas can give various ultrasound images and a proper diagnosis is sometimes difficult. Nevertheless, the most common ultrasound finding associated with RPT is an echogenic mass ${ }^{8,34-35,55,57-68}$ (Figs 9A to C, 10A and B, 11A and $\mathrm{B}, 12 \mathrm{~A}, 13 \mathrm{~A}$ to $\mathrm{C}$ and $14 \mathrm{~A}$ ). In contrast, Edwards et $\mathrm{al}^{15}$ found in his study an echogenic mass on day 7 in $51 \%$ of normal cases, in $21 \%$ on day 14 and in $6 \%$ on day 21 . He questioned ultrasound finding of an echogenic mass in uterine cavity as a sign of RPT. However, the definition of an echogenic mass was not specified and we may hypothesize that others investigators would probably classify many of their 'echogenic mass' as 'heterogeneous patterns'. A heterogeneous pattern is a common and insignificant finding of the involuting uterus ${ }^{13}$ (Figs 4B and 5C to D). It is located in the cervical area in the early puerperium, in the whole uterine cavity in the middle part of the puerperium and it is not common during late postpartum period. ${ }^{13}$ Sokol et al ${ }^{16}$ used the same classification and found 'echogenic material' in $40 \%$ of women 48 hours after a normal delivery. However, 14 of the 16 cases demonstrated echogenic material in the lower uterine segment, while only two had such findings in the fundus. It is unclear if 'echogenic material' is the same as 


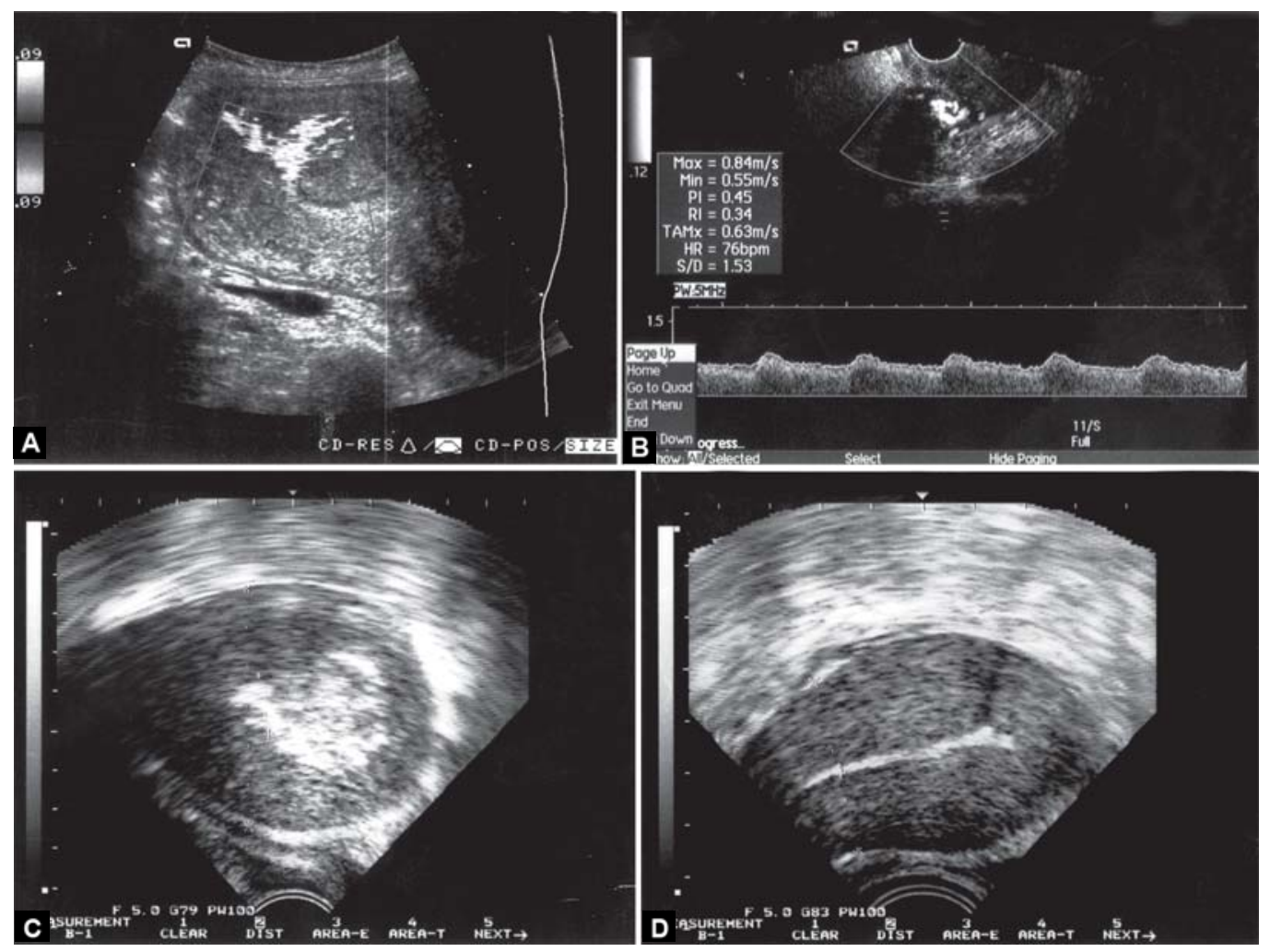

Figs 9A to D: Puerperal abnormalities revealed by ultrasound: (A) Retained placental tissue 2 days postpartum; (B) Blood flow in relation to retained placental tissue; (C) Retained placental tissue 6 weeks postpartum; (D) After curettage a thin, echogenic endometrium
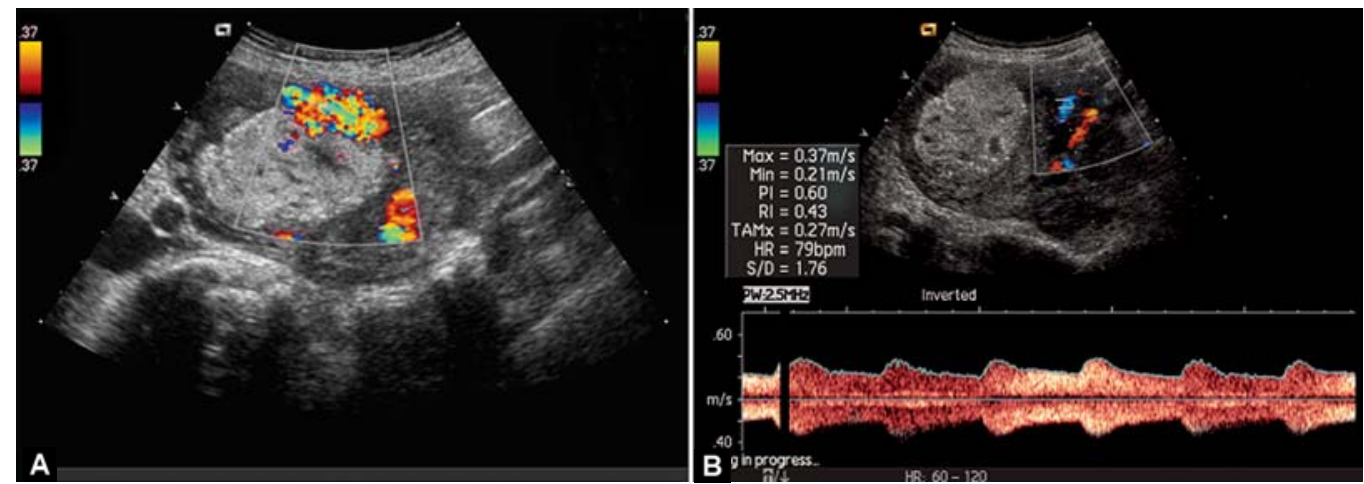

Figs 10A and B: Puerperal abnormalities revealed by ultrasound: (A) Transabdominal transverse scan, 9 days postpartum, shows retained placental tissue seen as an echogenic mass; (B) A low resistance blood flow is seen on one side of the echogenic mass
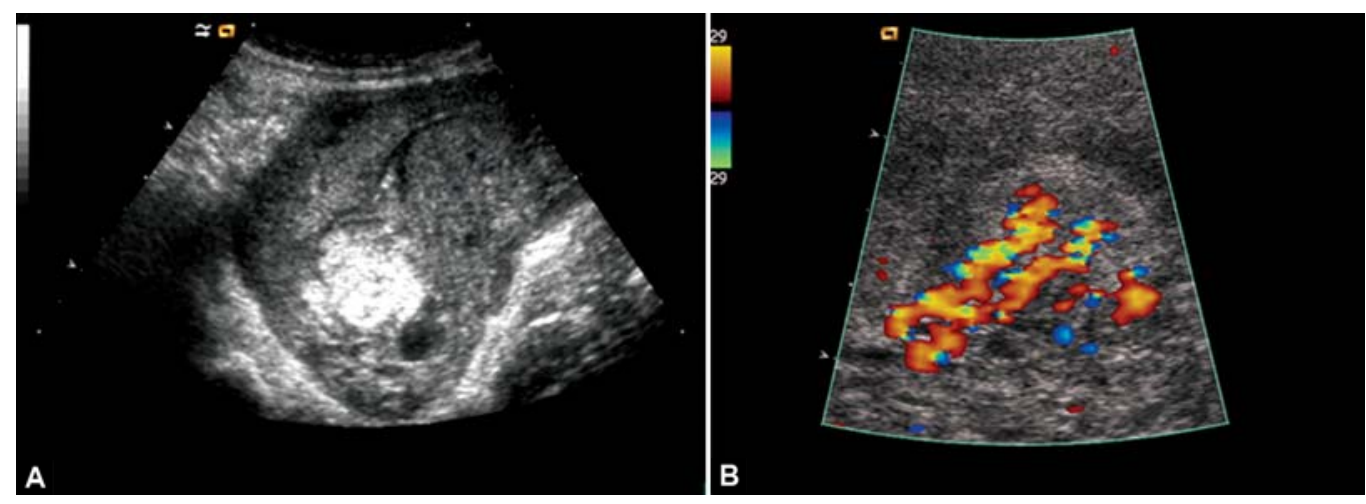

Figs 11A and B: (A) Transvaginal longitudinal scan shows retained placental tissue 6 weeks postpartum; (B) By color Doppler, feeding vessels are seen inside the echogenic mass 


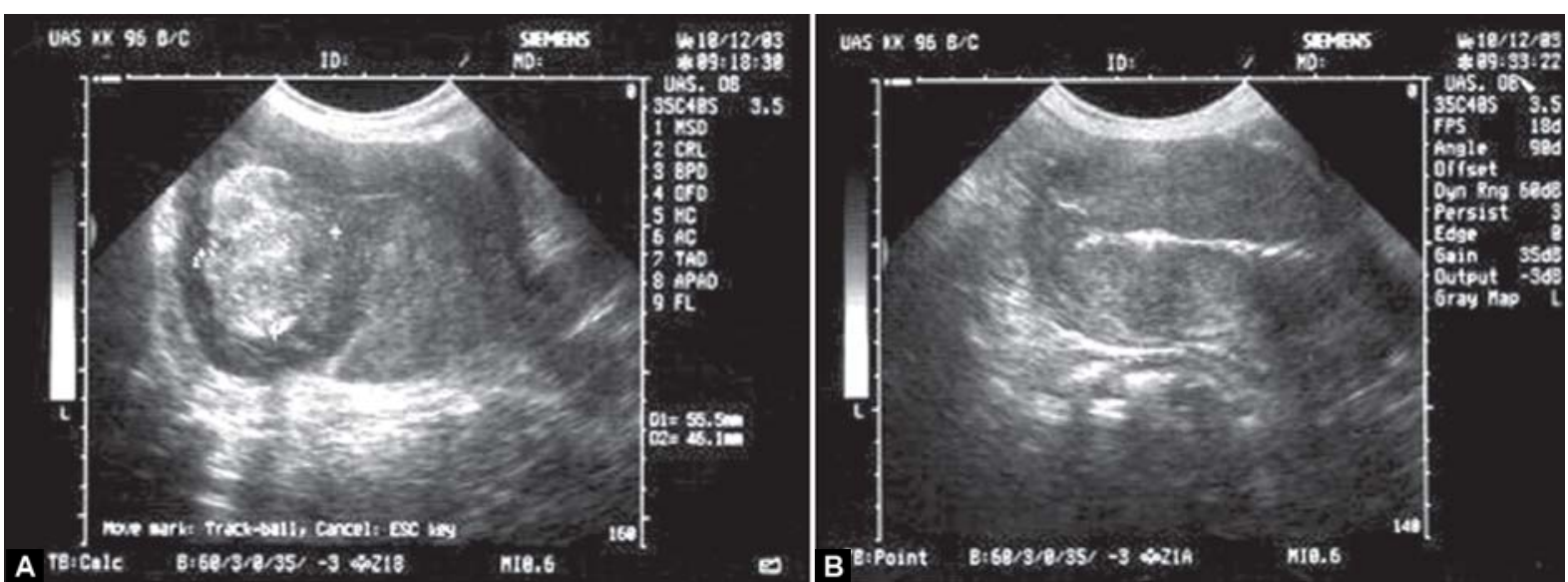

Figs 12A and B: (A) Transabdominal GD: longitudinal scan, 11 days postpartum, shows retained placental tissue seen as an echogenic mass; (B) A thin echogenic endometrium is visible soon after curettage
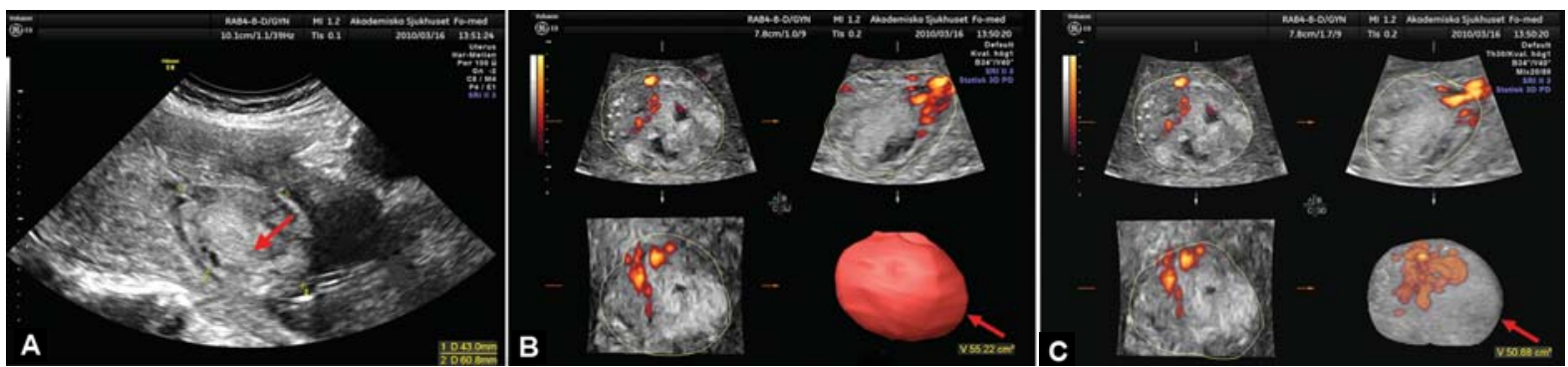

Figs 13A to C: (A) Transabdominal longitudinal scan of the uterus on day 17 postpartum. Suspected retained placental tissue seen as an echogenic mass in the uterine cavity (red arrow); (B) 3D USG shows the volume of the suspected retained placental tissue; (C) Power Doppler angiography, glass body mode shows vessels in the placental tissue (red arrow)

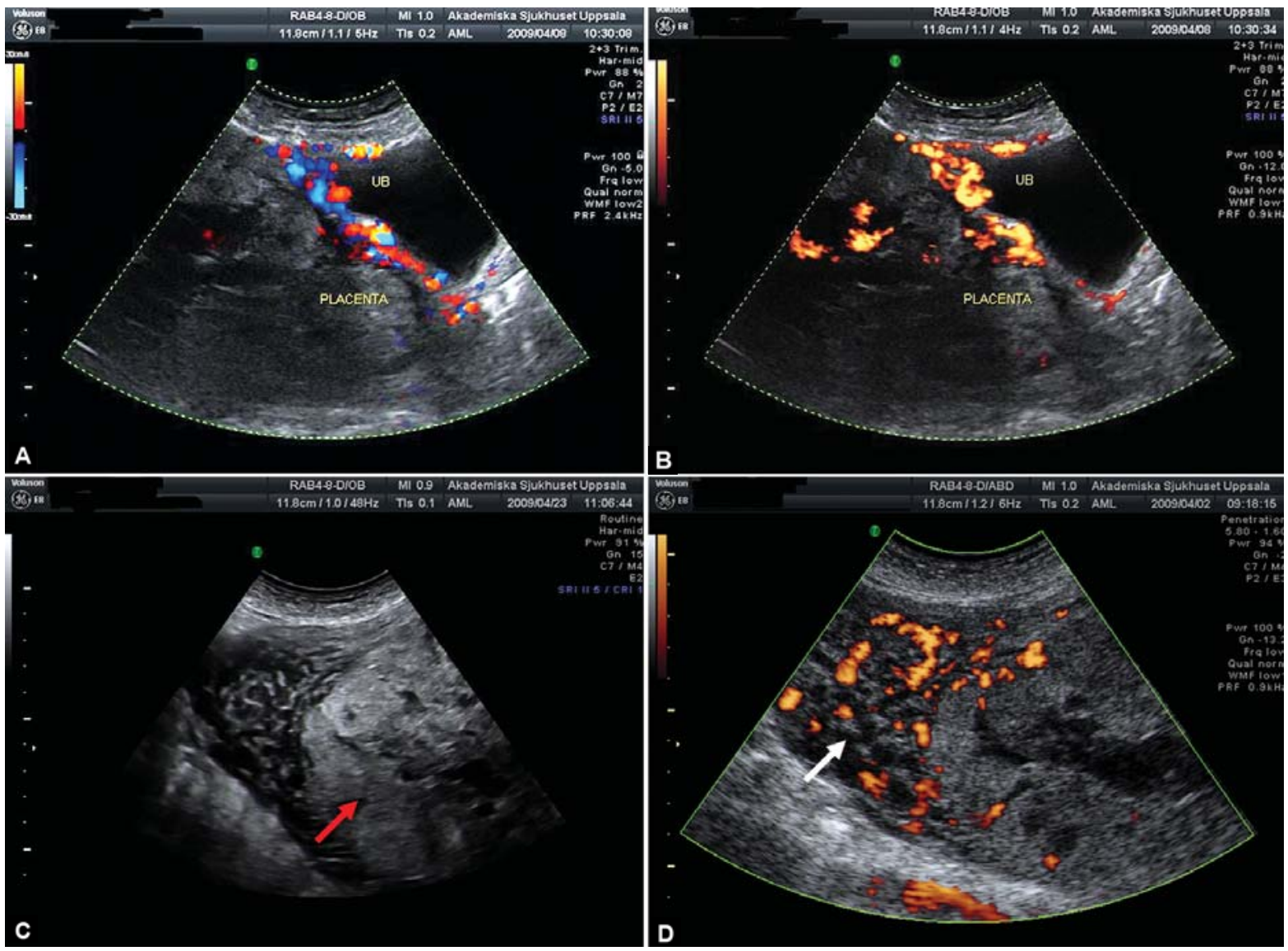

Figs 14A to D: Ultrasound image of placenta praevia perccreta left in situ: (A) Color Doppler and; (B) Power Doppler show the interface between the uterus and urinary bladder 7 days after cesarean section; (C) Retained placenta occupies the most part of the uterine cavity (arrow); (D) Power Doppler shows increased myometrial vascularity behind the retained placenta (arrow) 
an 'echogenic mass' or if it might be a mixed echo pattern. If dysfunctional postpartum bleeding persists for a long time, RPT is highly suspected. Hertzberg et $\mathrm{al}^{34}$ described socalled 'stippled pattern' of scattered hyperechogenic foci that later on became increasingly generalized echogenic, reflected secondary regressive changes in RPT (Figs 9C and 11A).

Two studies ${ }^{61,62}$ compared the diagnostic accuracy of clinical assessment with transabdominal USG in the management of SPH and concluded that both methods were of limited value. In contrast, recently published studies that assessed diagnostic accuracy of combined clinical and sonographic protocol, concluded that the combined approach was accurate and highly sensitive tool for the diagnosis of retained placental tissue. ${ }^{66-69}$

There are many reasons for discrepancies in the published reports. Factors that might explain the low sensitivity and high false-positive rate include a vague definition of the USG diagnosis of RPT, ${ }^{58-62}$ retrospective study design ${ }^{34,60,64,65}$ and mixed study populations including women with bleeding after an abortion and women with postpartum hemorrhage. ${ }^{8,60,64-66}$ Three studies often cited in the published literature evaluated asymptomatic women. ${ }^{55,58}$ The accuracy of postpartum USG for detection of RPT was calculated either from a small proportion of women who underwent curettage, assuming that women who had an uneventful puerperal course after conservative treatments had no RPT, ${ }^{34,60-62}$ or from histological findings among asymptomatic women. ${ }^{55,58}$ Finally, the patients and clinicians have not been blinded to the sonographic results in any of the published studies. If ultrasound finding shows an empty cavity with thin white decidua/endometrium during early (Figs 2A and 4A) or late puerperium (Figs 4C, $5 \mathrm{D}, 6 \mathrm{~A}$ and 9D), pure fluid/heterogeneous content in the cavity during the middle part of the puerperium (Figs 4B and 5B and C), or only small echolucent or hyperechogenic dots throughout whole postpartum period, a clinically significant amount of retained placental tissue is unlikely. ${ }^{13,34}$ Transvaginal ultrasound with high frequency probe as well as transvaginal sonohysterography may better differentiate intrauterine puerperal pathology. ${ }^{74-77}$

\section{Doppler Ultrasound During Pathological Puerperium}

A few studies investigated pulsed and color Doppler during puerperium in order to improve diagnostic accuracy of ultrasound regarding RPT. ${ }^{60,74,75}$ Some investigators observed low resistance blood flow around intracavitary contents $^{74-78}$ (Figs 9A and 10A). Ashiron et al ${ }^{74}$ measured resistance index (RI) in relation to RPT and found that diagnosis is highly suspected if $\mathrm{RI}$ is below 0.35 (Fig. 9B).
These patients are suitable for invasive treatment. RI above 0.45 should exclude diagnosis. Values between 0.35 and 0.45 form a 'gray zone' (Fig. 10B). Conservative treatment and repeated ultrasound examinations should be performed.

Power Doppler seems to be a new unexplored modality that could improve our abilities to diagnose clinically significant RPT. Retained placental tissue in the uterine cavity might cause a delay in the normal involution of uterine vessels. ${ }^{40,41}$ By color Doppler ultrasound, a localized area of increased vascularity within the myometrium may be detected. ${ }^{47,78-83}$ The presence of a hypervascular area in the myometrium, within or close to the echogenic mass, has previously been interpreted alternatively as a common physiological finding, ${ }^{47}$ as a finding associated with the presence of $\mathrm{RPT}^{60,74,75,83,84}$ or with arteriovenous (AV) malformations. ${ }^{25,78,79}$ Pulsed Doppler usually demonstrates a low resistance turbulent flow with high systolic velocity, resembling AV malformations. It has recently been suggested that curettage should not be performed on patients who present with SPH and a color Doppler image of a hypervascular area within the myometrium. ${ }^{78,79}$ Van den Bosch $^{80}$ examined 385 consecutive postpartum women and reported that a hypervascular area in the uterus was relatively common (8.3\%) and disappeared either spontaneously or after removal of placental remnants. Mungen ${ }^{81}$ has drawn attention to a tendency to overdiagnose true AV malformations. He pointed out that a majority of hypervascular areas in the myometrium probably represented normal 'perivillous flow' in the spiral arteries. The regression period may be prolonged in the presence of RPT. Only in very rare instances do they represent true arteriovenous malformations. In our recent work on angiographic embolization for treatment of major postpartum hemorrhage, no true AV malformation was diagnosed among 20 patients but four cases had pseudoaneurysm ${ }^{85}$ (Figs 15A and B).

Our knowledge on uterine artery flow in women with RPT is sparse. It could be that RPT prevents the physiological changes in uterine blood flow during the puerperium. The results of our small study ${ }^{83}$ showed the resistance flow indices in uterine artery below the 10th percentile for 8 of $20(40.0 \%)$ women of which seven had histological confirmation of RPT and one did not. There was, however, considerable overlap. No patient had resistance indices above the 90th percentile. In 12 of 20 (60.0\%) patients, an early diastolic notch was absent. Early diastolic notches appeared relatively late compared to the findings in normal population. Only one woman had a notch before postpartum day 28. Color Doppler showed a hypervascular area close to the echogenic mass in 12 of 20 (60\%) patients, all with histologically confirmed RPT. This figure is slightly higher 


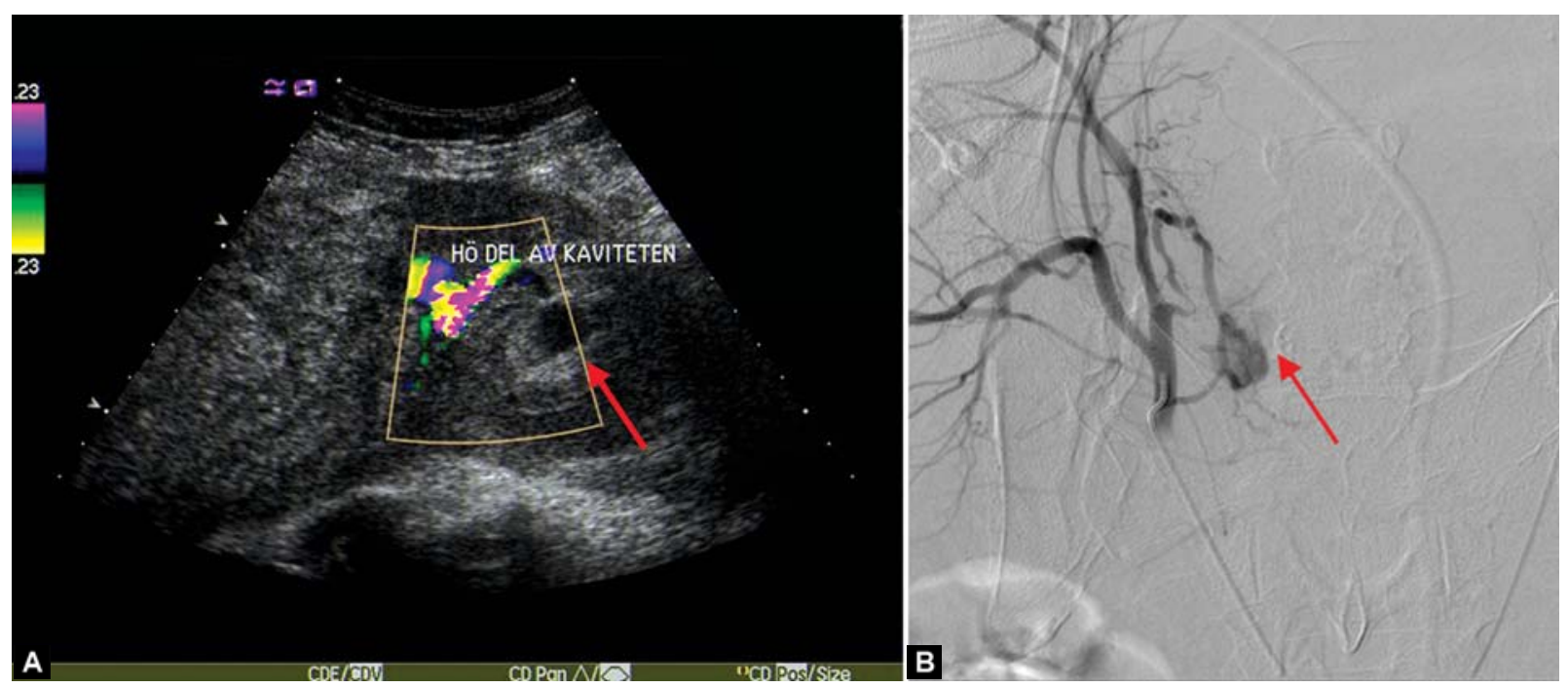

Figs 15A and B: (A) Transabdominal scan of the uterus on day 8 postpartum shows a huge defect in the uterus forming a pseudoaneurysm (arrow). Color Doppler reveals a feeding damaged uterine artery; (B) Angiography confirmed the ultrasound finding

than that reported by Durfee et $\mathrm{al}^{60}(55 \%)$ and by Zalel et $\mathrm{al}^{77}(46 \%)$. A hypervascular area was absent in eight patients $(40 \%)$ of which six had an echogenic mass that was histologically confirmed RPT. Our findings that the absence of blood flow does not exclude RPT are in concordance with previously reported results..$^{60,77}$

\section{POSTPARTUM ENDOMETRITIS}

Postpartum endometritis is a fairly common clinical condition, affecting 2 to $5 \%$ women following delivery. ${ }^{86,87}$ Cesarean section (CS) is the leading predisposing factor. ${ }^{88}$ It has been considered that the typical ultrasound finding in cases of endometritis is the presence of gas in the uterine cavity. ${ }^{10}$ Madrazo found gas in uterine cavity in $15 \%$ of patients with puerperal endometritis. ${ }^{10}$ Nowadays, infections caused by gas-forming organisms $\mathrm{C}$ perfringens are very rare and large gas-bubbles are almost never seen. Moreover, Wachsberg and Kurtz ${ }^{36}$ detected gas in about 19\% of normal cases, which is in accordance with results of a computed tomographic study performed within 24 hours of uncomplicated vaginal delivery (21\%). Ultrasound appearance of gas is seen as an intensively hyperechogenic focus equivalent in echogenicity to bowel gas with clean and dirty shadowing or a reverberation artefact. ${ }^{89}$ According to our experience, gas is mostly observed following intrauterine manipulations ${ }^{90}$ (Figs 12B and 16A) although it is occasionally observed after normal vaginal delivery. ${ }^{13}$ The detection of gas within the uterine cavity may be a normal finding during the puerperium and does not necessarily indicate the presence of endometritis or RPT. ${ }^{13,36}$ After CS or intrauterine manipulations highly echogenic foci can obscure an existing mass in the uterine cavity or be mistaken for retained placental tissue. ${ }^{34,90}$ Thus, whenever
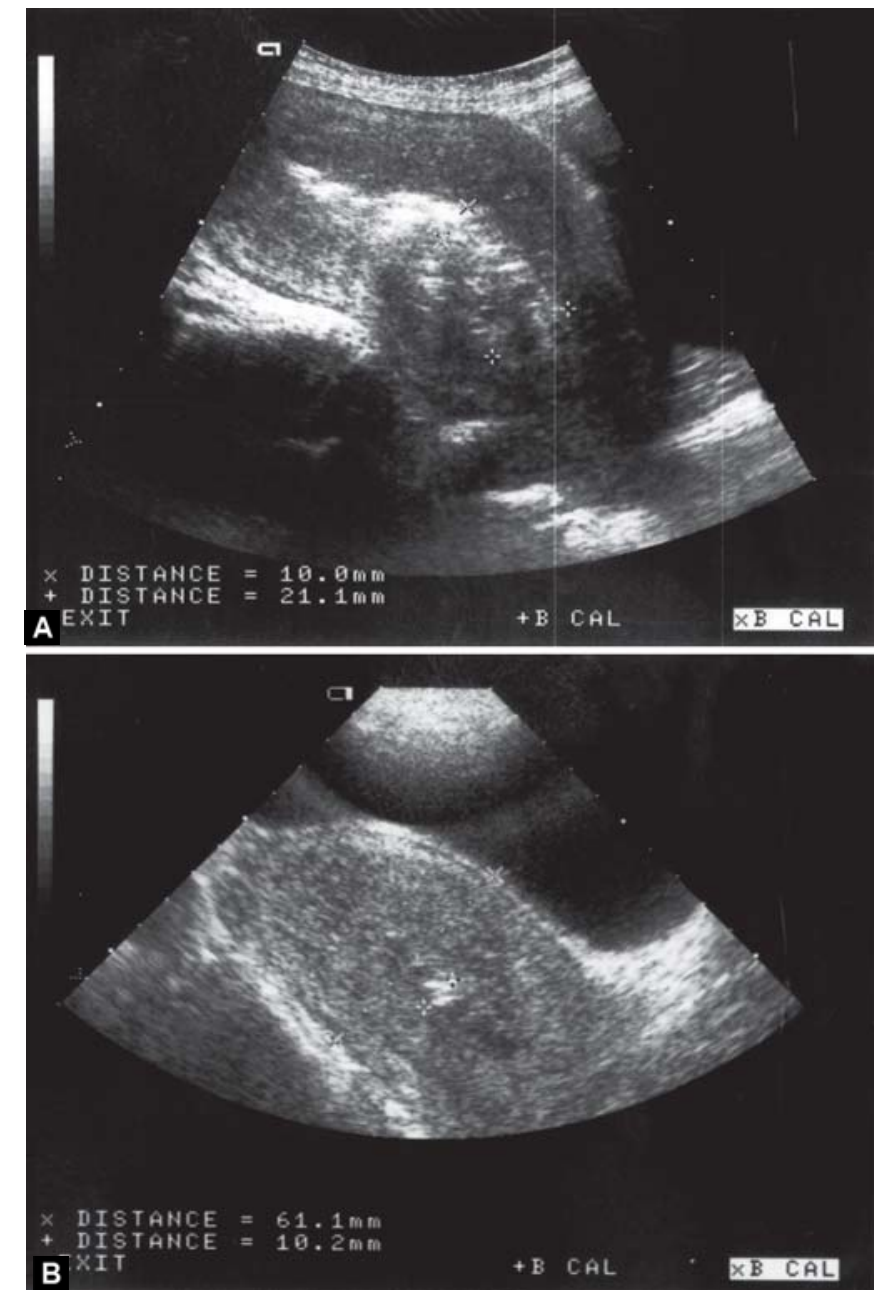

Figs 16A and B: (A) Gas in uterine cavity one-day post-curettage; (B) Six days postcurettage

highly echogenic foci are present in the uterine cavity, the physician who interprets ultrasound finding must be aware of recent uterine manipulations. Gas usually disappears within 1 to 2 weeks after instrumentation ${ }^{90}$ (Fig. 16B). 
Furthermore, it has been claimed that ultrasound image of RPT and endometritis overlap. ${ }^{8,52}$ Results from published studies on this issue are inconsistent. ${ }^{8,41,52-53,62,70,90}$ Pelage et $\mathrm{al}^{91}$ described 14 cases with uncontrollable SPH undergoing selective angiographic embolization. Six of 14 patients had clinical and ultrasound signs of endometritis with RPT. In four cases, histological confirmation was obtained. Two patients had pure endometritis. Conversely, Kong et $\mathrm{al}^{41}$ pointed out that endometritis appeared to be an overstated cause of SPH. He found that less than $5 \%$ of cases could be ascribed to endometritis. Ben-Ami et $\mathrm{al}^{62}$ found that a majority of the patients presenting with fever $>38^{\circ} \mathrm{C}$ postpartum were falsely diagnosed by ultrasound as having suspected RPT.

The presence of RPT may result in intrauterine infection and in these cases ultrasound examination can help us to select patients suitable for invasive treatment. In the vast majority of cases of isolated endometritis, ultrasound findings are normal and have no pathognomonic ultrasound image. ${ }^{35,90}$ Kirkinen et al ${ }^{45}$ found that blood flow to the infected uterus could be different from normal. Deutchman and Hartman described postpartum pyometra as a lucent area within the uterus. ${ }^{92}$ They also advocated the usage of Ultrasound to assist in guiding a drainage procedure. Septic pelvic thrombophlebitis, well known as an 'enigmatic puerperal fever' is another uncommon complication of the puerperium. It most commonly presents in early postpartum period and antibiotic treatment is usually unsuccessful. Rudoff et $\mathrm{al}^{93}$ suggests ultrasound examination in case of clinical suspicion of pelvic thrombophlebitis. Although ultrasound diagnosis of ovarian vein thrombophlebitis is well described, ${ }^{94-96}$ the diagnosis is still difficult and an ultrasound expertise is needed. Asymmetric dilatation of the ovarian or other pelvic vein may sometimes be observed. ${ }^{95}$ Furthermore a complex or hypoechoic mass near the lower pole of the kidney particularly in clinical setting of an 'enigmatic puerperal fever' should suggest thrombo- phlebitis. An echogenic intracaval mass is considered diagnostic and anticoagulation treatment should be added. ${ }^{96}$

\section{Cesarean Section}

Nowadays, when CS rates are continuously rising, higher incidence of all puerperal complications can be expected. ${ }^{88}$ The ultrasound image of the uterus following CS usually shows three distinctive patterns:

1. Gas in the cavity.

2. A small rounded area at the incision site that reflects tissue reaction due to localized edema.

3. Several echogenic dots at the incision site, which is related to the type of closure and the suture material used $^{82,90,97}$ (Figs 17A and B). All these characteristics are normal findings and no correlation with pathological conditions is found. The involution rate of the uterus following CS is not markedly different from the involution rate after vaginal delivery. ${ }^{90,98-100} \mathrm{We}$ observed a few morphological differences between the women delivered by CS and the women who had a vaginal delivery, such as the less common; anteverted position of the uterus and the empty uterine cavity in early puerperium, which might reflect slightly delayed uterine involution process. ${ }^{90}$ The significant infectious morbidity is associated with $\mathrm{CS}^{88}$ Ultrasound may be useful in postpartum women with clinical suspicion of a postoperative complication like phlegmona, ${ }^{101}$ abscess, pyometra, hematometra (Fig. 17C), wound infection, subfascial hematoma or intra-abdominal postoperative hemorrhage. Baker et al described bladder flap hematoma after a low uterine transverse CS. ${ }^{102}$ A solid or complex mass between the posterior bladder wall and the anterior uterine wall may be observed by ultrasound. An abscess appears as a cystic structure with internal debris surrounded by thicker irregular walls. An infected hematoma initially has similar ultrasound appearance. During the resolution process, it may change and appears more solid. However, the physician must be aware that

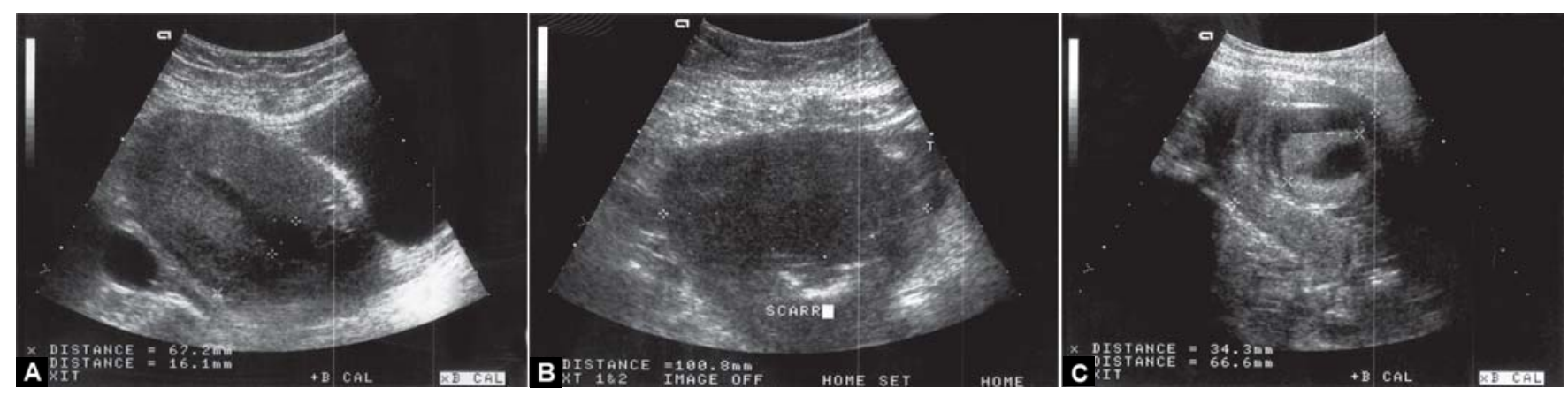

Figs 17A to C: $(A)$ The uterus after cesarean section-longitudinal section; (B) Coronal section—hyperechogenic scar in lower uterine segment; (C) Hematometra 
ultrasound diagnosis is just a complement and clinical condition of the patient should guide the therapeutic approach.

\section{UNCOMMON BUT POTENTIALLY LIFE-THREATENING CAUSES OF POSTPARTUM BLEEDING}

There are a few uncommon but potentially life-threatening causes of postpartum bleeding which contribute significantly to maternal mortality and morbidity. These are placenta accreta/increta/percreta, ${ }^{17-23}$ vessel's lesions (true AV malformations, ${ }^{25}$ pseudoaneurysm ${ }^{26-31}$ ) placental site tumor $^{32}$ and choriocarcinoma.

\section{Placenta Accreta/Increta/Percreta}

The incidence of abnormal placentation, placenta accreta/ increta/percreta, has increased in recent years, particularly due to the increasing rates of cesarean section. It is the most common factor for uncontrolled postpartum hemorrhage leading to emergency postpartum hysterectomy, which is associated with significant maternal morbidity and mortality. ${ }^{17}$ Antenatal diagnosis of severe invasive placentation is feasible with ultrasound. Both, conventional 2D and 3D ultrasound have been used and several reports have been recently published. ${ }^{18-23}$ Optimal management strategies for placenta accreta is highly dependent on accurate antenatal diagnosis and it is also associated with decreased maternal morbidity. ${ }^{103,104}$ Placenta accreta may be left in situ, as the whole or just partly ${ }^{103}$ and ultrasound may be of help to monitor spontaneous resorption of the retained tissue. However, the reports about ultrasound findings in these cases are $\operatorname{sparse}^{24}$ (Figs 14A to D).

\section{Uterine Arteriovenous Lesions (True AV Malformations, Acquired AV Malformations/ Pseudoaneurysm)}

True arteriovenous malformations (AV) are a rare errors of morphogenesis, which do not regress spontaneously and they are extremely rare causes of SPH. ${ }^{25,81}$ In contrast, acquired $\mathrm{AV}$ abnormalities of the uterus are associated with trauma after previous intrauterine procedures, RPT, infection or malignancy and are more common. ${ }^{26-31}$ The difference between normal perivillous blood flow increased myometrial flow related to RPT and AV malformations seems to be difficult. ${ }^{25,47,81}$ Three typical ultrasound signs of pseudoaneurysm include: A pulsating hypoechoic area connected to feeding artery by a narrow neck on Gray-scale ultrasound, a turbulent flow inside the pseudoaneurysm on color Doppler and a reversed flow on the neck of the pseudoaneurysm on pulse Doppler. During systole, blood enters the pseudoaneurysm and during diastole it reverses back into the uterine artery because of the pressure gradient between the pseudoaneurysm and the feeding artery (Figs 15A and B). Curettage should not be performed on patients who present with severe postpartum bleeding and a pseudoaneurysm is suspected on color Doppler scan. Further investigation with pelvic angiography or MRI should be performed.

\section{Placental Site Tumor and Choriocarcinoma}

These are rare forms of gestational trophoblastic disease and ultrasound image is difficult to distinguish them from each other as well as from retained placenta accreta and from acquired arteriovenous lesions. MRI findings are more sensitive but not specific. Thus, the appropriate diagnosis may be delayed.

Placental site tumor ${ }^{32}$ and choriocarcinoma may appear as an irregular mass with both cystic and hyperechoic components in the cavity often involving myometrium (Figs 18A and B). With color Doppler, low-resistance flow may be seen.

\section{CONGENITAL UTERINE MALFORMATIONS}

The prevalence of the congenital uterine malformations in general population is largely unknown. Failed fusion of the two Mullerian ducts to form the genital organs may cause reproductive, fetal and maternal hazards (infertility, premature labor, abnormal fetal presentations, retained placental tissue and postpartum hemorrhage). It is well known that uterine anomalies may remain undiscovered except when they are associated with reproductive or obstetric problems. Already in 1976, Bennett suggested puerperal ultrasonic hysterography as a screening procedure prior to radiological examination in women whose reproductive performance suggests a diagnosis of congenital malformation of the uterus. ${ }^{105}$ Since then, a few studies concerning the issue were published. Szoke and Kiss ${ }^{106}$ in 1977, manually examined patients, revealing a uterus differing in shape from normal, the patient had a breach presentation in her previous or present pregnancy and the involution of the uterus was slow. The ultrasound echo technique was applied and uterine anomalies were found in five cases postpartum. ${ }^{106}$ In 1984, Land et al performed ultrasonic hysterography in 104 patients between the 2nd and 5th postpartum day. An unexpectedly high number of women (16\%) showed an abnormal uterine configuration. ${ }^{107}$

The coronal section seems to be the most appropriate section in order to reveal uterine cavity anatomy (Figs 19A to C). ${ }^{13,82}$ It is difficult to obtain the coronal section by 

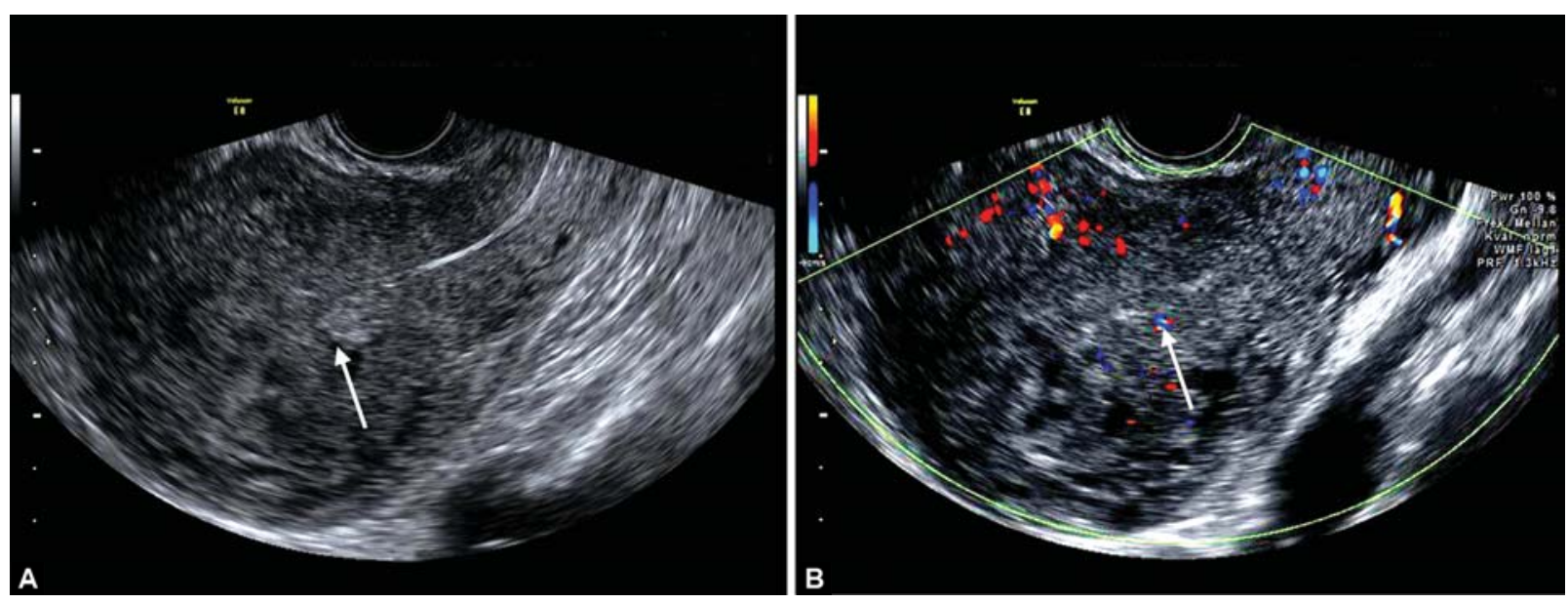

Figs 18A and B: (A) Transvaginal, longitudinal scan shows an irregular heterogeneous mass in the cavity involving the myometrium (arrow); (B) By color Doppler moderately increased myometrial vascularity is seen. Histological finding was choriocarcinoma
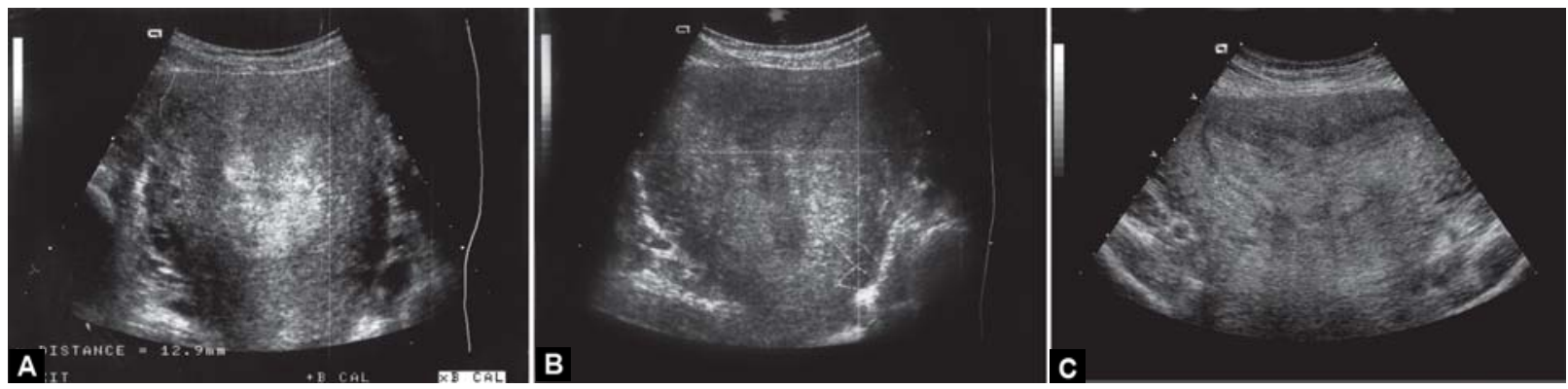

Figs 19A to C: (A) A coronal section shows a subseptate uterus one day after manual evacuation of the placenta; (B) The uterus of the same patient 8 days later; (C) A coronal section on day 3 postpartum shows uterus arcuatus in a woman who had twice breach position and preterm delivery

abdominal examination in nonpregnant patients. However, the puerperium when the uterus is extremely large makes an exception. The ultrasound examination should perform in the early puerperium because a large uterus lies in near proximity to the ultrasound probe and highly echogenic decidua outlines well the shape of the cavity. Puerperal ultrasound might detect uterine developmental abnormality, providing an explanation for complications in labor and the puerperium (Fig. 19C).

\section{Postpartum Urinary Retention}

Postpartum urinary retention is a relatively common condition and incidence ranges between 1 and $18 \%{ }^{108}$ According to the International Continence Society, $100 \mathrm{ml}$ is considered as the upper limit of residual urine. Ultrasound is the method of choice when assessing urinary bladder and residual urine postpartum. Invasive catheterization with the discomfort and the risk of infection can be avoided. Conventional bladder scanner is not to be recommended during the puerperium. Large uterus may have content of fluid and thus a misinterpretation may be done. Many different techniques for bladder volume measurement are used and the accuracy of the method varies widely. We
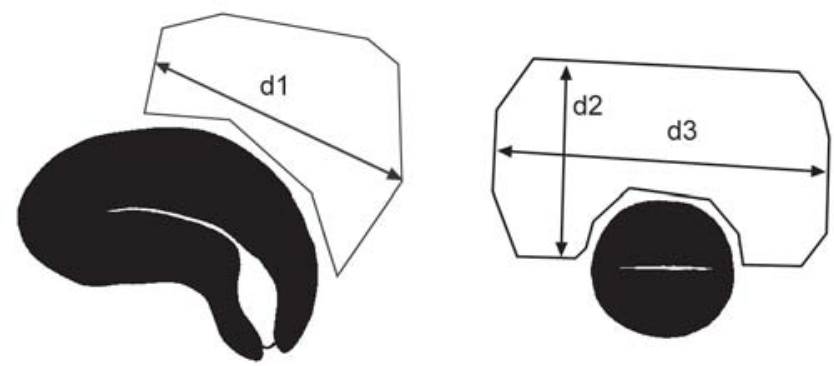

Fig. 20: Residual urine volume measurement

prefer a method where the longest distance of the maternal bladder (d1) is measured in a longitudinal section, and then two perpendicular diameters ( $\mathrm{d} 2$ and $\mathrm{d} 3$ ) are measured in the transverse section (Fig. 20). The estimated amount of residual urine can be calculated using the formula for approximation of the ellipsoid:

$$
\text { Volume }(\mathrm{ml})=(\mathrm{d} 1 \times \mathrm{d} 2 \times \mathrm{d} 3) / 2(\text { Figs } 13 \mathrm{~A} \text { to } \mathrm{C}) \text {. }
$$

\section{Puerperal Mastitis and Breast Abscess}

Puerperal mastitis is a common complication in lactating women, particularly in primiparous women. Reported incidence varies from 1 to $24 \% .{ }^{109}$ If treatment with 


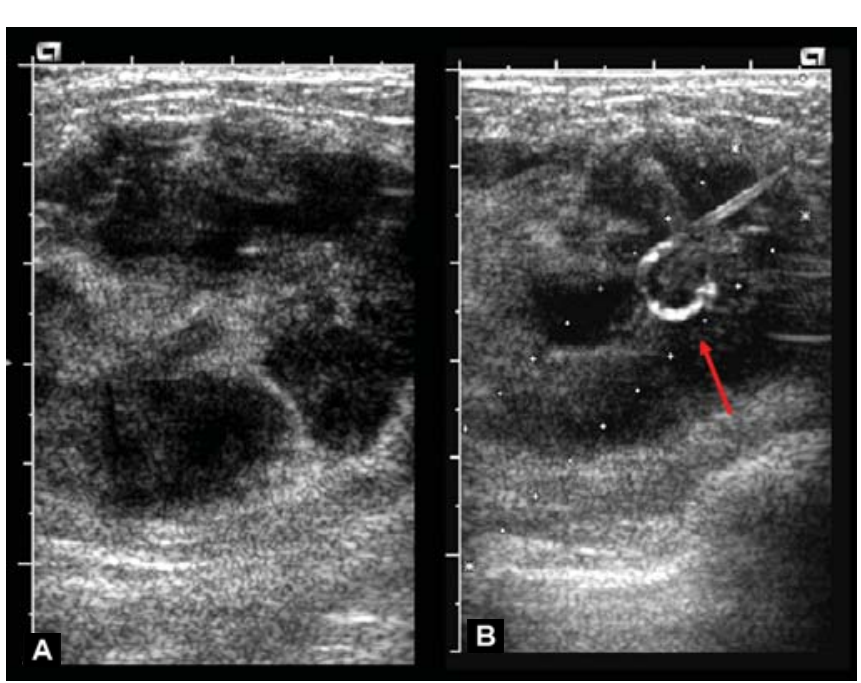

Figs 21A and B: (A) Ultrasound image of breast abscess before drainage with pigtail catheter; (B) After drainage with pigtail catheter (arrow)

antibiotics is delayed or inadequate it can progress to more serious complication, breast abscess. Breast tenderness limits clinical assessment and clinical diagnosis may be difficult, particularly if the abscess lies deeply in the breast or if it is too small. Ultrasound with a 7.5 to $12 \mathrm{MHz}$ probes is being used to differentiate abscess from puerperal mastitis. ${ }^{109}$ Ultrasound findings of mastitis are increased parenchyma/fat echogenicity, skin thickening and increased vascularity by color Doppler. Ultrasound diagnosis of breast abscess, in contrast, is made when a round/oval or irregular hypoechogenic lesion is detected (Fig. 21A). Color Doppler detects any vessels. The traditional treatment of breast abscess by surgical incision and drainage requires general anesthesia, major duct may be damaged and it usually makes a poor cosmetic result due to scar formation. More recently USG guided needle aspiration of breast abscess or catheter placement was used instead of surgical treatment. Ulitzsch et al ${ }^{109}$ reported ultrasound treatment of 56 breast abscesses among 43 breastfeeding women and the treatment was successful in all but one woman. In 52\% of cases repeat needle aspirations were required. The authors recommended a 21 gauge needle aspiration alone if the abscess diameter $<3 \mathrm{~cm}$. In contrast an abscess $>3 \mathrm{~cm}$ should treat with placement of pigtail catheter (Fig. 21B) which should be removed when ultrasound shows no residual fluid and when only minimal saline can be irrigated into the residual cavity. Breast-feeding is not contraindicated. However, in cases of recurrence, lactation stop with dopamine agonist is to be required.

\section{CONCLUSION}

Present ultrasound technology with high image resolution has made ultrasound a valuable diagnostic tool for assessing numerous postpartum clinical conditions. Suspicion of retained placental tissue, unknown cause of the puerperal sepsis, surgical complications or acute abdominal pain are some of the possible reasons to switch on ultrasound machine. Not only the involution changes of the uterus or pathological changes in uterine cavity but also the other organs like kidneys, urinary bladder, gallbladder, ovaries and abdominal cavity can be easily examined by ultrasound during postpartum period.

Sonohysterography may better differentiate intrauterine pathology by injecting saline under sonographic control and so improve the accuracy of the diagnosis of puerperal pathology.

Color, pulsed and power Doppler have improved our ability to study for the first time the vascular changes of the uterine involution noninvasively. With three-dimensional ultrasound, the possibility to measure volumes of the uterus and the cavity postpartum has been introduced. Uterine vascular network can also be investigated by 3D PD angiography more extensively.

More studies are required in this important area and all these new modalities need further evaluation. Moreover, the knowledge obtained through ultrasound examinations can help us to better understand both the physiology and patophysiology of the puerperium. The usefulness of ultrasound examinations during puerperium is not questioned any more, but ultrasound has become the first imaging modality used whenever, puerperal complications are suspected.

\section{REFERENCES}

1. Hytten F. The clinical physiology of the puerperium. London, UK: Farrand Press; 1996.

2. Donald I, MacVicar J, Brown TG. Investigation of abdominal masses by pulsed ultrasound. Lancet 1958;1(7032):1188-95.

3. Robinson HP. Sonar in the puerperium. A means of diagnosing retained products of conception. Scott Med J 1972;17(11): 364-66.

4. Szoke B, Kiss D. The use of the ultrasonic echo technique in examining the normal and pathological involution in the puerperium. Int J Gynaecol Obstet 1976;14(6):513-16.

5. Malvern J, Campbell S. Ultrasonic scanning of the puerperal uterus following postpartum haemorrhage. J Obstet Gynaecol Br Commonw 1973;80(4):320-24.

6. Rodeck CH, Newton JR. Study of the uterine cavity by ultrasound in the early puerperium. Br J Obstet Gynaecol 1976; 83(10):795-801.

7. Defoort P, Benijts G, Thiery M, et al. Ultrasound assessment of puerperal uterine involution. Eur J Obstet Gynaecol 1978; 8(2):95-97.

8. Lee CY, Madrazo B, Drukker BH. Ultrasonic evaluation of the postpartum uterus in the management of postpartum bleeding. Obstet Gynaecol 1981;58(2):227-32. 
9. VanRees D, Bernstine RL, Crawford W. Involution of the postpartum uterus: An ultrasonic study. J Clin Ultrasound 1981;9(2):55-57.

10. Madrazo BL. Postpartum sonography. The principle and practice of ultrasonography in obstetrics and gynecology (3rd ed). East Norwalk: Appleton-Century-Crofts 1985;449-56.

11. Lavery JP, Shaw LA. Sonography of the postpartum uterus. J Ultrasound Med 1989;8:481-86.

12. Wachsberg RH, Kurtz AB, Levine CD, et al. Real-time ultrasonographic analysis of the normal postpartum uterus: technique, variability and measurements. J Ultrasound Med 1994;13:215-21.

13. Mulic-Lutvica A, Bekuretzion M, Axelsson O, et al. Ultrasonic evaluation of the uterus and uterine cavity after normal, vaginal delivery. Ultrasound Obstet Gynecol 2001;18:491-98.

14. Tekay A, Jouppila P. A longitudinal Doppler ultrasonographic assessment of the alterations in peripheral vascular resistance of uterine arteries and ultrasonographic findings of the involuting uterus during the puerperium. Am J Obstet Gynecol 1993;168(1 Pt 1):190-98.

15. Edwards A, Ellwood DA. Ultrasonographic evaluation of the postpartum uterus. Ultrasound Obstet Gynecol 2000;16(7): 640-43.

16. Sokol ER, Casele H, Haney EI. Ultrasound examination of the postpartum uterus: What is normal? J Maternal Fetal Neonat Med 2004;15(2):95-99.

17. Rossi AC, Lee RH, Chmait RH. Emergency postpartum hysterectomy for uncontrolled postpartum bleeding: A systematic review. Obstet Gynecol 2010;115(3):637-44.

18. Chou MM, Ho ESC, Lee YH. Prenatal diagnosis of placenta previa accreta by transabdominal color Doppler ultrasound. Ultrasound Obstet Gynecol 2000;15(1):28-35.

19. Yang JI, Lim YK, Kim HS, et al. Sonographic findings of placental lacunae and the prediction of adherent placenta in women with placenta previa totalis and prior Cesarean section. Ultrasound Obstet Gynecol 2006;28(2):178-82.

20. Japaraj RP, Mimin TS, Mukudan K. Antenatal diagnosis of placenta previa acreta in patients with previous cesarean scar. J Obstet Gynaecol Res 2007,33(4),431-37.

21. Bauer ST, Bonanno C. Abnormal placentation. Semin Perinatol 2009;33:88-96.

22. Shin JC, Jaraquemada JMP, Su YN, et al. Ultrasound Obstet Gynecol 2009;33:193-203.

23. Chou M-M, Chen W-C, Tseng J-J, et al. S-C Prenatal detection of bladder wall involvement in invasive placentation with sequential two-dimensional and adjunctive three-dimensional ultrasonography. Taiwan J Obstet Gynecol 2009;48(1):38-45.

24. Shapiro JL, Sherer DM, Hurley JT, et al. Postpartum ultrasonographic findings associated with placenta accreta. Am J Obstet Gynecol 1992;167(3):601-02.

25. Kelly SM, Belli AM, Campbell S. Arteriovenous malformation of the uterus associated with secondary postpartum hemorrhage. Ultrasound Obstet Gynecol 2003;21(6):602-05.

26. Henrich W, Fuchs I, Luttkus A, et al. Pseudoaneurysm of the uterine artery after cesarean delivery: Sonographic diagnosis and treatment. J Ultrasound Med 2002;21(12):1431-34.

27. Cooper BC, Hocking-Brown M, Sorosky JI, et al. Pseudoaneurysm of the uterine artery requiring bilateral uterine artery embolization. J Perinat 2004;24(9):560-62.

28. Eason DE, Tank RA. Avoidable morbidity in a patient with pseudoaneurysm of the uterine artery after cesarean section. J Clin Ultrasound 2006;34(8):407-11.
29. Mammen T, Shanthakumari H, Gopi K, et al. Iatrogenic secondary postpartum haemorrhage: Apropos of two uncommon cases. Australas Radiol 2006;50(4):392-94.

30. McGonegle SJ, Scott Dziedzic T, Thomas J, et al. Pseudoaneurysm of the uterine artery after an uncomplicated spontaneous vaginal delivery. J Ultrasound Med 2006;25(12): 1593-97.

31. Marnela K, Saarelainen S, Palomäki O, et al. Sonographic diagnosis of postpartum pseudoaneurysms of the uterine artery: A report of 2 cases. J Clin Ultrasound 2010;38(4):205-08.

32. Vaswani K, Vitellas KM, Bennet WF, et al. Sonography case of the day. Am J Roentgenol 2000;175:895-901.

33. Williams JW. Regeneration of the uterine mucosa after delivery with special reference to the placental site. Am J Obstet Gynecol 1931;22:640, 664.

34. Hertzberg BS, Bowie JD. Ultrasound of the postpartum uterus, prediction of retained placental tissue. J Ultrasound Med 1991;10:451-56

35. Sakki A, Kirkinen P. Ultrasonography of the uterus at early puerperium. Eur J Ultrasound 1996;4:99-105.

36. Wachsberg RH, Kurtz AB. Gas within the endometrial cavity at postpartum US. A normal finding after spontaneous vaginal delivery. Radiology 1992;183(2):431-33.

37. Sharman A. Reproductive physiology of the postpartum period. Livingston: Edinburgh E and S; 1966.

38. Oppenheimer LW, Sherriff EA, Goodman JDS, et al. The duration of lochia. Br J Obstet Gynaecol 1986;93:754-57.

39. Visness CM, Kennedy KI, Ramos R. The duration and character of postpartum bleeding among breast-feeding women. Obstet Gynecol 1997;89(2):159-63.

40. Andrew AC, Bulmer JN, Wells M, et al. Subinvolution of the uteroplacental arteries in the human placental bed. Histopathology 1989;15(4):395-405.

41. Khong TY, Khong TK. Delayed postpartum hemorrhage: A morphologic study of causes and their relation to other pregnancy disorders. Obstet Gynecol 1993;82(1):17-22.

42. Weydert JA, Benda JA. Subinvolution of the placental site as an anatomic cause of postpartum uterine bleeding. A Review. Arch Pathol Lab Med 2006;130:1538-42.

43. Campbell S, Diaz-Recasen J, Griffin D, et al. New Doppler technique for assessing uteroplacental blood flow. Lancet 1983;1(8326 Pt 1):675-77.

44. Bernstein IM, Ziegler WF, Leavitt $\mathrm{T}$, et al. Uterine artery hemodynamic adaptations through the menstrual cycle into early pregnancy. Obstet Gynecol 2002;99(4):620-24.

45. Kirkinen P, Dudenhausen J, Baumann H, et al. Postpartum blood flow velocity waveforms of the uterine arteries. J Reprod Med 1988;33(9):745-48.

46. Jaffa AJ, Wolman I, Har-Toov J, et al. Changes in uterine artery resistance to blood flow during puerperium: A longitudinal study. J Matern-Fetal Invest 1996;6:27-30.

47. Van Schoubroeck D, Van den Bosch T, Scharpe K, et al. Prospective evaluation of blood flow in the myometrium and uterine arteries in the puerperium. Ultrasound Obstet Gynecol 2004;23(4):378-81.

48. Mulic-Lutvica A, Eurenius K, Axelsson O. Longitudinal study of Doppler flow resistance indices of uterine artery after normal vaginal delivery. Acta Obstet Gynecol Scand 2007;86(10): 1207-14.

49. Belachew J, Mulic-Lutvica A, Eurenius K. Three-dimensional ultrasound of the uterus postpartum. Abstract, Presented as an oral poster at 20th World Congress on ultrasound in Obst and Gynecol in Prag 10-14 October, 2010. 
50. Alexander J, Thomas P, Sanhghera J. Treatments for secondary postpartum haemorrhage. The Cochrane Library, Issue 4:2002.

51. Dewhurst C. Secondary postpartum hemorrhage. J Obstet Gynaecol Br Commonwealth 1966;73:53-58.

52. Rome RM. Secondary postpartum haemorrhage. Br J Obstet Gynaecol 1975;82(4):289-92.

53. King PA, Duthie SJ, Dong ZG, et al. Secondary postpartum haemorrhage. Aust NZ Obstet Gynaecol 1989;29(4):394-98.

54. Hoveyda F, MacKenzie IZ. Secondary postpartum haemorrhage: Incidence, morbidity and current management. Br J Obstet Gynaecol 2001;108(9):927-30.

55. Carlan SJ, Scott WT, Pollack R, et al. Appearance of the uterus by ultrasound immediately after placental delivery with pathologic correlation. J Clin Ultrasound 1997;25(6):301-08.

56. Jones RF 3rd, Warren BL Jr, Thorton WN Jr. Planned postpartum exploration of uterus cervix and vagina. Obstet Gynecol 1996;27(5):699-702.

57. Shalev J, Royburt M, Fite G, et al. Sonographic evaluation of the puerperal uterus: Correlation with manual examination. Gynecol Obstet Invest 2002;53(1):38-41.

58. Shen O, Rabinowitz R, Eisenberg VH, et al. Transabdominal sonography before uterine exploration as a predictor of retained placental fragments. J Ultrasound Med 2003;22(6):561-64.

59. Sadan O, Golan A, Girtler O, et al. Role of sonography in the diagnosis of retained products of conception. J Ultrasound Med 2004;23(3):371-74.

60. Durfee SM, Frates MC, Luong A, et al. The sonographic and color Doppler features of retained products of conception. J Ultrasound Med 2005;24(9):1181-86.

61. Neill AMC, Nixon RM, Thornton S. A comparison of clinical assessment with ultrasound in the management of secondary postpartum haemorrhage. Eur J Obstet Gynecol Reprod Biol 2002;104(2):113-15.

62. Ben-Ami I, Schneider D, Maymon R, et al. Sonographic versus clinical evaluation as predictors of residual trophoblastic tissue. Hum Reprod 2005;20(4):1107-11.

63. Mulic-Lutvica A, Axelsson O. Ultrasound finding of an echogenic mass in women with secondary postpartum hemorrhage is associated with retained placental tissue. Ultrasound Obstet Gynecol 2006;28(3):312-19.

64. Rufener SL, Adusumilli S, Weadock WJ, et al. Sonography of uterine abnormalities in postpartum and postabortion patients. A potential pitfall of interpretation. J Ultrasound Med 2008;27(3):343-48.

65. Kamaya A, Petrovitch I, Chen B, et al. Retained products of Conception: Spectrum of color Doppler Findings. J Ultrasound Med 2009;28(8):1031-41.

66. Van den Bosch T, Daemen A, Van Schoubroeck D, et al. Occurrence and outcome of residual trophoblastic tissue. J Ultrasound Med 2008;27(3):357-61.

67. Matijevic R, Knezevic M, Grgic O, et al. Diagnostic accuracy of sonographic and clinical parameters in the prediction of retained products of conception. J Ultrasound Med 2009;28(3):295-99.

68. Wolman I, Altman E, Faith G, et al. Combined clinical and ultrasonographic work-up for the diagnosis of retained products of conception. Fertil Steril 2009;92:1162-64.

69. Wolman I, Altman E, Faith G, et al. Evaluating retained products of conception in the setting of an ultrasound unit. Fertil Steril 2009;91(4):1586-88.

70. Pather S, Ford M, Reid R, et al. Postpartum curettage: An audit of 200 cases. Aust N Z J Obstet Gynaecol 2005;45(5):368-71.
71. Jensen PA, Stromme WB. Amenorrhhea secondary to puerperal curettage (Asherman's syndrom). Am J Obstet Gynecol 1972;113:150-57.

72. Westendorp IC, Ankum WM, Mol BW, et al. Prevalence of Asherman's syndrome after secondary removal of placental remnants or a repeat curettage for incomplete abortion. Hum Reprod 1998;13(12):3347-50.

73. Al-Inany H. Intrauterine adhesions. An update. Acta Obstet Gynecol Scand 2001;80:986-93.

74. Achiron R, Goldenberg M, Lipitz S, et al. Transvaginal duplex Doppler ultrasonography in bleeding patients suspected of having residual trophoblastic tissue. Obstet Gynecol 1993;81(4):507-11.

75. Alcazar JL, Lopez-Garcia G, Zornoza A. A role of color velocity imaging and pulsed Doppler sonography to detect retained trophoblastic tissue. Ultrasound Obstet Gynecol 1996; 8(Suppl 1):41.

76. Wolman I, Hartoov J, Amster R, et al. Transvaginal sonohysterography for the early detection of residual trophoblastic tissue. Ultrasound Obstet Gynecol 1986;8:37.

77. Zalel Y, Gamzu R, Lidor A, et al. Color Doppler imaging in the sonohysterographic diagnosis of residual trophoblastic tissue. J Clin Ultrasound 2002;30(4):222-25.

78. Timmerman D, Van Den Bosch T, Peeraer K, et al. Vascular malformations in the uterus: Ultrasonographic diagnosis and conservative management. Eur J Obstet Gynecol Reprod Biol 2000;92(1):171-78.

79. Timmerman D, Wauters J, Van Calenbergh S, et al. Color Doppler imaging is a valuable tool for the diagnosis and management of uterine vascular malformations. Ultrasound Obstet Gynecol 2003;21(6):570-77.

80. Van den Bosch T, Van Schoubroeck D, De Brabanter J, et al. Color Doppler and gray- scale ultrasound evaluation of the postpartum uterus. Ultrasound Obstet Gynecol 2002;20(6): 586-91.

81. Müngen E. Vascular abnormalities of the uterus: Have we recently over-diagnosed them? Opinion. Ultrasound Obstet Gynecol 2003;21:529-31.

82. Mulic-Lutvica A, Axelsson O. The chapter labor and puerperium in the section ultrasound in perinatal medicine in the Textbook of Perinatal Medicine, July 2001.

83. Mulic-Lutvica Ajlana, Eurenius K, Axelsson O. Uterine artery Doppler ultrasound in postpartum women with retained placental tissue. Acta Obstet Gynecol Scand 2009;88(6):724-28.

84. Kido A, Togashi K, Koyama Y, et al. Retained products of conception masquerading as acquired arteriovenous malformation. J Comput Assist Tomogr 2003;27(1):88-92.

85. Eriksson LG, Mulic-Lutvica A, Jangland L, et al. Massive postpartum hemorrhage treated with transcatheter arterial embolization: Long-term effects, implication on fertility and technical considerations. Acta Radiologica 2007;48:635-42.

86. Stovall TG, Ambrose SE, Ling FW, et al. Short-term course antibiotic therapy for the treatment of chorioamnionitis and postpartum endomyometritis. Am J Obstet Gynecol. 1998;159(2):404-07.

87. Calhoun BC, Brost B. Emergency management of sudden puerperal fever. Obstet Gynecol Clin North Am 1995;22(2): 357-67.

88. Zelop C Heffner LJ. The downside of caesarean delivery; shortand long-term complications. Clin Obstet Gynecol 2004;47: 386-93. 
89. Carson PL. Clean and dirty shadowing at US: A reappraisal. Radiology 1991;181:231-36.

90. Mulic-Lutvica A, Axelsson O. Postpartum ultrasound in women with postpartum endometritis, after cesarean section and after manual evacuation of the placenta. Acta Obstet Gynecol Scand 2007;86:210-17.

91. Pelage JP, Soyer P, Repiquet D, et al. Secondary postpartum hemorrhage: Treatment with selective arterial embolization. Radiology 1999;212:385-89.

92. Deutchman ME, Hartmann KJ. Postpartum pyometra: A case report. J Fam Pract 1993;36:449-52.

93. Rudoff JM, Astranskas LJ, Rudoff JC, et al. Ultrasonographic diagnosis of septic pelvic thrombophlebitis. J Ultrasound Med 1988;7:287-91.

94. Warhit JM, Fagelman D, Goldman MA, et al. Ovarian vein thrombophlebitis: Diagnosis by ultrasound and CT. J Clin Ultrasound 1984;12:301.

95. Wilson PC, Lerner RM. Diagnosis of ovarian vein thrombophlebitis by ultrasonography. J Ultrasound Med 1983;2:187.

96. Sherer DM, Fern S, Mester J, et al. Postpartum ultrasonographic diagnosis of inferior vena cava thrombus associated with ovarian vein thrombosis. Am J Obstet Gynecol 1997;177(2):474-75.

97. Burger NF, Dararas B, Boes EGM. An echogenic evaluation during the early puerperium of the uterine wound after caesarean section. J Ultrasound Med 1983;2:18.

98. Meyenburg M, Schulze-Hagen K, Schaller G. Involution of the uterus following vaginal or abdominal delivery. Z Geburtshilfe Perinatol 1983;187(4):200-02.

99. Negishi H, Kishida T, Yamada H, et al. Changes in uterine size after vaginal delivery and caesarean section determined by vaginal sonography in the puerperium. Arch Gynecol Obstet 1999;263(1-2):13-16.

100. Koskas M, Nizard J, Salomon LJ, et al. Abdominal and pelvic ultrasound findings within 24 hours following uneventful cesarean section. Ultrasound Obstet Gynecol 2008;32(4): 520-26.
101. Lavery JP, Howell RS, Shaw L. Ultrasonic demonstration of a phlegmona following caesarean section: Case report. J Clin Ultrasound 1985;13:134-36.

102. Baker ME, Bowie JD, Killan AP. Sonography of postcaesareansection bladder-flap hematoma. Am J Roentgenol 1984;144: 757-59.

103. Sentilhes L, Ambroselli C, Kayem G, et al. Maternal outcome after conservative treatment of placenta accreta. Obstet Gynecol 2010;115(3):526-34.

104. Warshak CR, Ramos GA, Eskander R, et al. Effect of predelivery diagnosis in 99 consecutive cases of placenta accreta. Obstet Gynecol 2010;115(1):65-69.

105. Bennett MJ. Puerperal ultrasonic hysterography in the diagnosis of congenital uterine malformations. Br J Obstet Gynaecol 1976;83(5):389-92.

106. Szoke B, Kiss D. The use of ultrasonic echo technique in the diagnosis of developmental anomalies of the uterus. Ann Chir Gynaecol 1977;66(1):59-61.

107. Land JA, Stoot JE, Evers JL. Puerperal ultrasonic hysterography. Gynecol Obstet Invest 1984;18(3):165-68.

108. Weissman A, Grisarn D, Shenhav M, et al. Postpartum surveillance of urinary retention by ultrasonography: The effect of epidural analgesia. Ultrasound Obstet Gynecol 1995;6: 130-34.

109. Ulitzsch D, Nyman MKG, Carlson RA. Breast abscess in lactating women: US guided treatment. Radiology 2004; 232(3):904-09.

\section{ABOUT THE AUTHOR}

\section{Ajlana Mulic-Lutvica}

Senior Consultant, Department of Obstetrics and Gynecology, FetalMaternal Medicine Unit, Uppsala University Hospital, Uppsala, Sweden, Phone: 46(0) 18/6110000, Fax: +46(0) 18/559775 e-mail: ajlana.lutvica@kbh.uu.se 